\title{
Synthesis, Crystal Structure, Computational studies and Spectroscopic characterization of a Hybrid Material Self-Assembly \\ From Tetra(isothiocyanate)cobalt(II) anion and 1-(4-methoxyphenyl)piperazinium
}

Chaima Gharbi ${ }^{1}$, Wataru Fujita ${ }^{2}$, Frédéric Lefebvre ${ }^{3}$, Werner Kaminsky ${ }^{4}$, C. Jelsch ${ }^{5}$, Chérif Ben Nasr $^{1}$, Lamia Khedhiri ${ }^{6, *}$

1 Laboratoire de Chimie des Matériaux, Université de Carthage, Faculté des Sciences de Bizerte, 7021 Zarzouna, Tunisie.

2 General Education, Faculty of Science and Technology, Seikei University, Kichijoji-kita machi, Musashino 180-8633, Japan.

3 Laboratoire de Chimie Organométallique de Surface (LCOMS), Ecole Supérieure de Chimie Physique Electronique, 69626 Villeurbanne Cedex, France.

4 Department of Chemistry, University of Washington, Seattle, Washington, USA.

$5 \mathrm{CRM}^{2}, \mathrm{CNRS}$, Université de Lorraine, Nancy, France.

6 Laboratoire des Matériaux Utiles, Institut National de Recherche et d'Analyse physicochimique (INRAP), Sidi Thabet, Tunis, Tunisie.

\begin{abstract}
A novel hybrid organic-inorganic molecular solid, 1-(4-methoxyphenyl)piperazinium (1-4MPPip) tetra(isothiocyanate)cobalt monohydrate (1-4MPPip) $)_{4}\left[\mathrm{Co}(\mathrm{NCS})_{4}\right]_{2} \cdot \mathrm{H}_{2} \mathrm{O}$ (I), was prepared using a slow evaporation growth technique at room temperature and characterized by elemental analysis, X-ray crystal structure, spectroscopic and computational studies. The crystal structural analysis reveals that the solid crystallizes in the triclinic space group $\mathrm{P} \overline{1}$. The $\left[\mathrm{Co}(\mathrm{NCS})_{4}\right]^{2-}$ anions are arranged in pairs along the $c$-axis direction to form anionic layers parallel to the $(a, c)$ plane. Intermolecular interactions were investigated by Hirshfeld surfaces
\end{abstract}


and contact enrichment tools. The organic entities are grouped into dimers through weak interactions $\mathrm{OW}-\mathrm{H} \ldots \mathrm{N}$ and $\mathrm{OW}-\mathrm{H} \ldots \mathrm{O}$ generated by the water molecules. The robustness of the crystal is also enhanced by $\mathrm{C}-\mathrm{H} \ldots \pi$ and $\mathrm{C}-\mathrm{H} \ldots \mathrm{S}$ intermolecular interactions. Mulliken charge distribution, molecular electrostatic potential (MEP) maps and HOMO and LUMO energy gaps have been computed. The vibrational absorption bands were identified by infrared spectroscopy. The solid-state UV-Visible absorption spectrum of the title compound was obtained at room temperature in order to spotlight the optical properties.

Keywords: tetra(isothiocyanate)cobalt(II) anion; crystal structure; IR, Hirshfeld surface; contact enrichment ratio; DFT calculations.

\section{Introduction}

Crystal engineering is a flourishing field of research in inorganic chemistry, progressing from analysis of crystal structures in terms of intermolecular interactions with interests in the modeling, design, synthesis and applications of crystalline solids. In this regard, coordination compounds are extensively studied due to their fascinating topologies as well as their potential applications in various areas.

A survey of the recent literature shows that much attention has been carried out on thiocyanate anions, highlighting the preparation of metal complexes containing the thiocyanate anion to improve their performance in various fields such as magnetism and photoluminescence [1-5]. It should be pointed out that the isothiocyanate anion is a polyvalent ligand that can coordinate to metal cations through $\mathrm{N}$ atom as a monodentate ligand in different ways leading to diverse coordination modes with a large structural variety. Particularly, the isothiocyanate species leads to a wide range of various molecular solids containing $\left[\mathrm{M}(\mathrm{NCS})_{4}\right]^{2-}\left(\mathrm{M}=\mathrm{Mn}^{2+}\right.$, 
$\mathrm{Co}^{2+}, \mathrm{Zn}^{2+}$ ), which may disclose enthralling magnetic behaviors, electronic, and optical properties [6-10]. Most of these expanded networks with multi-dimensional structures give rise either to one-dimensional [11-16], two-dimensional [17] or three-dimensional arrangements $[18,19]$. Due to partially filled d orbitals, transition metals can give many isomers creating different geometries.

Preliminary investigations showed that organic ligands with appropriate sizes and configurations were very worthwhile building block in the assembly of organic inorganic hybrid materials. Furthermore, the great significance gathered to explore piperazine and its derivatives in relatively recent years reflects the broad potential thanks to their excellent biological and pharmacology properties for the construction of drugs. Additionally, molecules holding piperazine entities can be useful as a result of various therapeutic activities notably antipsychotic, antiviral, anticancer, anti-inflammatory and antidepressant [20-23].

Our pertinent interest in this study is the association of cobalt-isothiocyanate anionic parts and organic cations with attractive physical properties [24-28] which should guide to fascinating new functional coordination materials. We report here the synthesis, crystal structure, Hirshfeld surface analysis and spectroscopic techniques of a new coordination compound (I).

\section{Experimental}

\subsection{Chemical preparation}

All chemicals were used without purification. The compound was obtained by mixing at room temperature $0.192 \mathrm{~g}(1 \mathrm{mmol})$ of 1-(4-methoxyphenyl)piperazine dissolved in $10 \mathrm{~mL}$ ethanol to $20 \mathrm{~mL}$ of an aqueous solution of $\mathrm{CoCl}_{2}(0.129 \mathrm{~g}, 1 \mathrm{mmol})$. A $20 \mathrm{~mL}$ aqueous solution of $\operatorname{KSCN}(0.194 \mathrm{~g}, 2 \mathrm{mmol})$ was carefully added under continuous stirring. A few drops of dilute $\mathrm{HCl}$ solution were added to acidify the solution to $\mathrm{pH}=2$. The final solution was heated 
at $80^{\circ} \mathrm{C}$ for $30 \mathrm{~min}$ and then evaporated slowly at room temperature. Blue crystals suitable for single crystal X-ray structure analysis were obtained after four days. Yield $=83 \%$. Anal. Calc. C, 45.42; H, 5.09; N, 16.30\%; Found: C, 45.57; H, 5.19; N, 13.18.

\subsection{Investigation techniques}

\subsubsection{X-ray single crystal structural analysis.}

A blue single crystal of (I) was carefully selected under a polarizing microscope in order to perform its structural analysis by X-ray diffraction. X-ray diffraction data were collected on a Rigaku AFC system with a Mercury CCD detector at $150 \mathrm{~K}$ using graphite-monochromated $\operatorname{MoK} \alpha(\lambda=0.71073 \AA)$ radiation. The frame data were integrated and corrected for absorption with the Rigaku/MSC CrystalClear package [29]. The structure was solved by a dual space method with the SHELXT program and refined by successive differential Fourier syntheses and a full-matrix least-squares procedure using the SHELXL program $[30,31]$ by a Rigaku/MSC Crystal Structure package [32]. All H atoms were initially located in a difference Fourier map and were refined with a riding model. $\mathrm{H}$ atoms were placed in geometrically idealized positions and constrained to ride on their parent atoms with C-H distances in the range 0.95-1.00 $\AA$. $U_{\text {iso }}$ values were fixed such that they were $1.2 U_{\text {eq }}$ of their parent atom $U_{\text {eq }}$ for CH's and $1.5 U_{\text {eq }}$ of their parent atom $U_{\text {eq }}$ in the case of methyl groups. The drawings were made with Diamond [33]. Crystal data and experimental parameters used for the intensity data collection are summarized in Table 1.

\subsubsection{Infrared spectroscopy}

The IR spectrum was recorded in the $4000-400 \mathrm{~cm}^{-1}$ range using a NICOLET IR 200 FT-IR infrared spectrophotometer. 


\subsection{3. $U V$-Vis spectroscopy}

The UV absorption and optical diffuse reflectance spectra were measured with a Perkin Elmer Lambda 11UV/ Vis spectrophotometer in the wavelength radiation varying between 200 and $800 \mathrm{~nm}$ at room temperature.

\subsubsection{Theoretical calculations}

The asymmetric unit contains two cobalt complexes, four organic ligands, and a water molecule. Each of these entities has been studied separately except the ligand which interacts with the water molecule which has been studied with it. With the exception of the infrared spectrum, this has no influence on the calculations, all calculations were made with Gaussian 09 and the B3LYP method. The base used was $6-31+G *$ except for cobalt for which the LanL2DZ pseudo-potential was chosen. For the cobalt complexes the coordinates are those of the X-rays, while for the organic ligands the positions of the protons were optimized beforehand with the same method.

\subsubsection{Hirshfeld surface}

The fingerprint plots of internal and external distances $\left(d_{\mathrm{i}}, d_{\mathrm{e}}\right)$ were obtained from CrystalExplorer3.1 [34]. The analysis of contact types and their enrichment [35] were computed with the MoProViewer program [36]. To obtain an integral Hirshfeld surface around each molecule (organic cation, $\mathrm{Co}(\mathrm{SCN})_{4}$, water) a set of moieties not in contact with each other were selected in the crystal packing. The $\mathrm{Co}(\mathrm{SCN})_{4}$ coordination complex was considered as a molecule in the Hirshfeld analysis. The more hydrophobic Hc hydrogen atoms bound to carbon were distinguished from those bound to oxygen and nitrogen $(\mathrm{Ho} / \mathrm{n})$.

\section{Results and discussion}

\subsection{X-ray diffraction study}

(I) crystallizes in a triclinic system with the $\mathrm{P} \overline{1}$ space group. The asymmetric unit comprises two tetra(isothiocyanate)cobalt $\quad\left[\mathrm{Co}(\mathrm{NCS})_{4}\right]^{2-}$ anions, four 1-(4- 
methoxyphenyl)piperazinium [1-4MPPip $]^{+}$cations and a water molecule (Fig.1). Selected bond distances and angles are given in Table 2.

For the $\left[\mathrm{Co}(\mathrm{NCS})_{4}\right]^{2-}$ anions, the coordination geometry of the central Co(II) ions can be described as a slightly distorted tetrahedron. The average Co-N bond distance is $1.956 \AA$ and the $\mathrm{N}-\mathrm{Co}-\mathrm{N}$ bond angles vary in the range $105.94-113.12^{\circ}$ for the anion containing the $\mathrm{Co} 1$ atom. For the second cobalt complex, containing the $\mathrm{Co} 2$ ion, the average Co-N coordination bond distance is $1.961 \AA$ and the $\mathrm{N}-\mathrm{Co}-\mathrm{N}$ bond angles vary from 106.13 to $111.80^{\circ}$. These values are in agreement with those found in complexes containing the $\left[\mathrm{Co}(\mathrm{NCS})_{4}\right]^{2-}$ anion $[37-$ 44]. Fig. 2 shows that the $\left[\mathrm{Co}(\mathrm{NCS})_{4}\right]^{2-}$ anions are arranged in pairs along the $c$-axis direction. These pairs lie at $(0,0,0)$ and $(1 / 2,0,1 / 2)$ to form anionic layers parallel to the $(a, c)$ plane (Fig. 3). The nearest $\mathrm{Co} \cdots$ Co distance is 6.869 (5) $\AA$.

For the organic entities, it was found that the neighboring cations containing the N11, $\mathrm{N} 12$ and N13, N14 atoms are grouped into dimers through weak interactions OW-H...N and OW-H...O generated by the water molecules (Fig. 4, Table 3). The projection of the complete atomic arrangement of (I) along the $a$-axis shows that the piperazine-1,4-dium cations link the $\left[\mathrm{Co}(\mathrm{NCS})_{4}\right]^{2-}$ anions via N-H...N and N-H...S interactions to give a three-dimensional network as shown in Fig. 5.

The robustness of the crystal is enhanced by three intermolecular interactions of C-H... type (Fig. 6) between the hydrogen atoms of the methyl groups and of the heterocycle, on the one hand, and of the neighboring aromatic ring, on the other hand, with H...plane distances of 3.352(2), 3.380(5) and 3.853(3) $\AA$. This result is compatible with those reported in the literature $[42,45,46]$.

Fig. 7 shows C-H...S interactions between the cations and anions. Except for the S6 atom, we notice that all $\mathrm{S}$ atoms of the $\left[\mathrm{Co}(\mathrm{NCS})_{4}\right]^{2-}$ anions are involved in $\mathrm{H}$-bonding interactions. S1, S4 and S8 atoms are double acceptors, while each one of S2, S3, S5 and S7 
sulfur atoms is involved in only one hydrogen bond. These weak interactions (Table 3) also improve the stability of the network.

\subsection{Quantum mechanical study}

Quantum chemical calculations were performed from the crystal data by using the Gaussian 09 program.

For the inorganic part, the calculations were made by the B3LYP method with the LanL2DZ pseudopotential for cobalt and the $6-31+\mathrm{G}^{*}$ base for the $\mathrm{C}, \mathrm{N}$ and $\mathrm{S}$ atoms. The results are almost identical for the two complexes and for the complex after total optimization except that in the latter case the HOMO and LUMO are degenerate states, the symmetry of the complex being $T_{\mathrm{d}}$. As a consequence, we will provide only one figure in each case. The HOMO and LUMO orbitals involve both a cobalt d orbital and an SCN ligand orbital, the difference being that for the HOMO this orbital is centered on the $\mathrm{N}$ and $\mathrm{S}$ atoms, while for the LUMO it is centered on the carbon (Fig. 8-a). The energy distribution of the different orbitals is shown in Fig. 8-b.

For the organic ligand, the calculations were made with the B3LYP/6-31+G* method for all atoms and optimization of the positions of the protons. As for the inorganic part, the results are identical for the four ligands and after total optimization. So here also only one figure is given each time. The HOMO orbital is localized on the aromatic ring, while the LUMO is found primarily on the $\mathrm{NH}_{2}{ }^{+}$group (Fig. 9-a). The energy distribution of the different orbitals is shown in Fig. 9-b.

Table 4 gives the energies of the various orbitals for the different entities. The large HOMO-LUMO energy gap values, between 3.16 and $4.07 \mathrm{eV}$, imply a high kinetic stability and a low chemical reactivity $[47,48]$. 


\subsection{Molecular Electrostatic Potential analysis}

The Molecular Electrostatic Potential (MEP) surface of this compound is depicted in Fig. 10. The MEP is used to determine the nuclear and electronic charge distribution of a given molecule. The maps were obtained at the B3LYP/6-31+G*-LANL2DZ level of theory. Moreover, blue and red colors indicate the positive and negative potentials, respectively. As it can be seen, the electrostatic potential maps are color-coded and are subdivided into many regions. For the inorganic part, the positive zone is located on the cobalt atom, while the negative zone is on carbon (Fig. 10-a). For the organic cation, the positive zone is on the $\mathrm{NH}_{2}$ group, while the negative is on the aromatic ring (Fig. 10-b).

\subsection{Mulliken population analysis}

The Mulliken charge distribution of all atoms in the title compound, obtained with the same method as above, is given in Tables 5 and 6 . All atoms in the asymmetric unit are listed. The atoms of the organic molecule are numbered as follows:

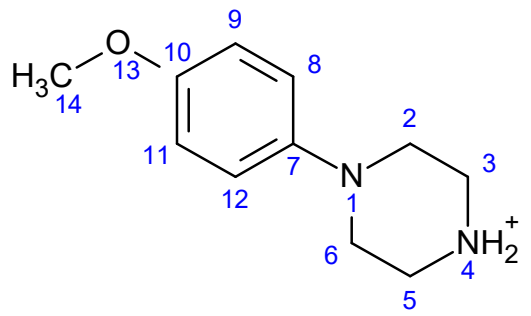

For the anionic part, the atomic charge distribution shows that the cobalt ion, as depicted by the Molecular Electrostatic Potential surface analysis, has a positive charge of 0.108, 0.129 and 0.158 for the full optimization, respectively. For each anionic $\left[\mathrm{Co}(\mathrm{NCS})_{4}\right]^{2-}$ complex, only one thiocyanate anion has a positive nitrogen charge, the three others having negative charges. All the $\mathrm{C}$ and $\mathrm{S}$ atoms have negative charges (Table 5). For the organic entity, the oxygen atoms have negative charges. All hydrogen atoms carry positive charge. For the carbon atoms, there are quite large fluctuations for the same atom from one ligand to another (see for example the 
C11 carbon) (Table 6) which are due to the different structures of the various ligands and which reflect the intermolecular interactions in the solid state.

\subsection{FT-IR spectrophotometry}

Fig. 11-a displays the IR spectrum of (I). Three characteristic vibrations can prove the presence of the thiocyanate ligand and its binding mode to the Co(II) ion center for the formation of the anionic complex $\left[\mathrm{Co}(\mathrm{NCS})_{4}\right]$.

The strong band at $2066 \mathrm{~cm}^{-1}$ can be assigned to the stretching vibration of the carbonnitrogen triple bond of thiocyanate ligand. The weak band at $831 \mathrm{~cm}^{-1}$ can be attributed to C-S bond stretching vibration. The weak band at $475 \mathrm{~cm}^{-1}$ can be ascribed to the bending vibration of N-C-S. This bending vibration of thiocyanate indicates the binding of thiocyanate ligand to $\mathrm{Co}(\mathrm{II})$ center via its $\mathrm{N}$-terminal atom. The assignment of these bands to thiocyanate vibrations and deduction of its coordination mode are based on previously reported results [49-53]. The spectrum shows also characteristic vibrations for 1-(4-methoxyphenyl)piperazinium cation ([14MPPip $]^{+}$). The broad bands in the range $3600-2300 \mathrm{~cm}^{-1}$ correspond to the stretching vibrations of the organic and hydroxyl groups $v(\mathrm{~N}-\mathrm{H}), v(\mathrm{C}-\mathrm{H})$ and $v(\mathrm{O}-\mathrm{H})$. The band at 1504 $\mathrm{cm}^{-1}$ corresponds to $v(\mathrm{C}=\mathrm{C})_{\mathrm{Ar}}$ stretching vibrations. The band at $1448 \mathrm{~cm}^{-1}$ with a shoulder at $1413 \mathrm{~cm}^{-1}$ can be assigned to the $\mathrm{CH}_{2}$ deforming. The bands at 1302 and $1244 \mathrm{~cm}^{-1}$ can be attributed to the $\mathrm{CH}_{2}$ wagging, followed by a band at $1180 \mathrm{~cm}^{-1}$, which is related to the ring deformation. The weak bands at 1146 and $1021 \mathrm{~cm}^{-1}$ can be assigned to the $\mathrm{CH}_{2}$ twisting. The weak band at $916 \mathrm{~cm}^{-1}$ can be attributed to the ring breathing. The weak band at $873 \mathrm{~cm}^{-1} \mathrm{can}$ be attributed to the ring deformation. Bands at 786, 707 and $536 \mathrm{~cm}^{-1}$ can be assigned to the $\mathrm{CH}_{2}$ rocking [54].

The calculated IR spectrum is given in Fig. 11-b. DFT calculations of the frequencies were made on the geometry obtained after optimization of the protons. This spectrum is very similar to the experimental one. A close agreement between the experimental and theoretical 
wave numbers $\left(R^{2}=0.989\right)$ is mostly achieved in the fingerprint region as shown in Fig. 12 . Thus, the precision is sufficient to assign the experimental frequencies and to confirm the attributions proposed above. It is worth to not that experimentally, only one band is observed for the thiocyanate groups, at $2066 \mathrm{~cm}^{-1}$, probably because the calculations were made on separate entities and not on a crystal.

\subsection{UV-Vis absorption spectral study}

The solid state UV-Vis spectrum of (I) (Fig. 13) in the region 200-800nm is attributed to the anionic portion of the solid. The two characteristic bonds at 620 and $330 \mathrm{~nm}$ are assigned as $\mathrm{d} \rightarrow \mathrm{d}$ and $\mathrm{L}(\pi) \rightarrow \mathrm{L}^{*}$, respectively, and are similar to those observed in [4$\mathrm{NO}_{2} \mathrm{BzPy}_{2}\left[\mathrm{Co}(\mathrm{NCS})_{4}\right][50],\left([\mathrm{BzPy}]_{2}\left[\mathrm{Co}(\mathrm{NCS})_{4}\right]\right)[44]$ and $\left([\mathrm{BzQl}]_{2}\left[\mathrm{Co}(\mathrm{NCS})_{4}\right]\right)[44]$.

To confirm these attributions, the UV-visible spectrum of each component of the asymmetric unit was calculated using the TD-DFT method with the LanL2DZ pseudopotential for cobalt and the base $6-31+\mathrm{G}^{*}$ for all other atoms. The number of excited states in the calculation was 40 .

The results are almost identical for the two cobalt complexes. In both cases, the calculation gives a band around $680 \mathrm{~nm}$ and one around $350 \mathrm{~nm}$ (Fig. 14). The components below $250 \mathrm{~nm}$ are not calculated with this calculation due to an insufficient number of excited states (all attempts to increase this number failed due to memory problems in the computer).

The results are also identical for the four organic ligands and also only one result (Fig. 15) is shown. Each spectrum shows several bands between 200 and $300 \mathrm{~nm}$ and a small component around $350-400 \mathrm{~nm}$. The inorganic part gives a band in this last zone of intensity (oscillator strength) 0.07 while each ligand has a component of intensity 0.01 . Consequently, the band around $350 \mathrm{~nm}$ is mainly due to the cobalt complex, the band around $700 \mathrm{~nm}$ being due solely to it. 
The small shift between calculated and measured wavelengths can be explained by the fact that the calculation is related to a molecule free from any interaction while, in the experimental data, the interactions between molecules in the crystal lattice are taken into consideration.

\subsection{Hirshfeld surface and contacts enrichment ratio}

The Hirshfeld surface is a region in space surrounding the molecules where the chemical nature of their intermolecular contacts can be analyzed. The contact enrichment, derived from the Hirshfeld surface, is computed from the ratio of the actual contacts $C_{\mathrm{xy}}$ in the crystal with those computed as if all types of contacts had the same probability to form [35]. The contact enrichment ratio is a powerful tool to deduce which type of contacts is over or under-represented in the crystal packing. An enrichment ratio larger than unity for a given pair of chemical species $\mathrm{X} \ldots \mathrm{Y}$ indicates that these contacts are favored (over-represented) in the crystal. The analysis of contact types and their enrichment were computed with the MoProViewer program [36].

The visualization of the Hirshfeld three-dimensional $d_{\text {norm }}$ surface of the compound is shown in Fig. 13. In this figure, the intensive red hot spots on the surface colored according to $d_{\text {norm }}$ indicate the presence of H...O, H...N and H...S contacts and are attributed to the interactions of types $\mathrm{O}-\mathrm{H} \cdots \mathrm{O}, \mathrm{O}-\mathrm{H} \cdots \mathrm{N}, \mathrm{N}-\mathrm{H}^{\cdots} \mathrm{O}, \mathrm{N}-\mathrm{H} \cdots \mathrm{S}, \mathrm{N}-\mathrm{H} \cdots \mathrm{N}, \mathrm{C}-\mathrm{H} \cdots \mathrm{O}$ and $\mathrm{C}-\mathrm{H} \cdots \mathrm{S}$, as revealed in the structural analysis (Table 3). The other blue and white spots were related to the H... H contacts.

The fingerprints plots of internal and external distances $\left(d_{\mathrm{i}}, d_{\mathrm{e}}\right)$ obtained from CrystalExplorer3.1 [35] are shown in Fig. 14 for the main contacts. There are spikes for O...H and $\mathrm{S} \ldots \mathrm{H}$ contacts at short distance as there are strong $\mathrm{H}$-bond donors $(\mathrm{H}-\mathrm{N}$ and $\mathrm{H}-\mathrm{O})$ in the title compound. The nitrogen atoms bound to three carbon atoms have $\mathrm{sp}^{3}$ hybridization and act as hydrogen bond acceptors at slightly longer distance. 
The chemical nature of contacts and their enrichment ratios in the title compound are shown in Table 7 and Fig. 15. The Hirshfeld surface of the ensemble is constituted by as much as $46.5 \%$ of hydrogen atoms followed by $\mathrm{S}(21.8 \%), \mathrm{C}(21.0 \%), \mathrm{N}(3.9 \%), \mathrm{Co}(3.7 \%)$ and $\mathrm{O}(3.1 \%)$. The major contacts are constituted by S...Hc (25.2\%) followed by C...Hc $(24.2 \%)$, Hc...Hc (10.6\%) and S...C (6.3\%).

The aromatic cycles of the four cations are all interacting with the hydrogen rich nonplanar $\mathrm{C}_{4} \mathrm{~N}_{2}$ cycle (head to tail dimers), which results in $\pi \ldots$ Hc weak hydrogen bonds, corresponding to abundant and enriched $(E=1.44) \mathrm{C} .$. Hc contacts. The other major contacts are S...C and Hc...Hc.

The strong H-bonds N...Ho/n $(E=5.23)$ and O...Ho/n $(E=4.97)$ are the most enriched contacts. Both S...Hc and S...Ho/n hydrogen bonds are enriched $(E=1.44$ and $E=1.36$ respectively).

The contacts on Hirshfeld surfaces of the four independent organic cations were analyzed. The contacts types are very similar on the four molecules as the correlation coefficient between the $C_{\mathrm{xy}}$ values of two cations is between 0.918 and 0.994 . The fingerprint plot of the contacts on only one cation was therefore computed.

The contacts types between the layer of $\mathrm{Co}(\mathrm{NCS})_{4}$ anions and the layer of organic cations plus water are shown in Table 8 . It shows that the S...Hc weak hydrogen bonds, constitute about half of the interface (49.4\%) and are enriched at $E=1.37$. The Hc...C, weak hydrogen bond, is the second major contact (14.5\%). The N-H...NCS strong hydrogen bonds are the most enriched contacts on the two layers interface $(E=4.14)$. 


\section{Conclusion}

A novel hybrid material, [1-4MPPip $]_{4}\left[\mathrm{Co}(\mathrm{NCS})_{4}\right]_{2} \cdot \mathrm{H}_{2} \mathrm{O}(\mathrm{I})$, has been synthesized and in its crystal structure the $\left[\mathrm{Co}(\mathrm{NCS})_{4}\right]^{2-}$ anions are arranged in pairs to form anionic layers parallel to the $(a, c)$ plane. The piperazine-1,4-dium cations link the $\left[\mathrm{Co}(\mathrm{NCS})_{4}\right]^{2-}$ anions via NH...N and N-H...S interactions to give a three-dimensional network. The robustness of the crystal is enhanced by H...O, H...N, H...S as well as three C-H... HOMO-LUMO energy gap suggests a good stability of the title compound. The Molecular Electrostatic Potential analysis reveals that, for the inorganic part, the positive zone is located on the cobalt atom, while the negative zone is on carbon, for the organic cation, the positive zone is on the $\mathrm{NH}_{2}$ group, while the negative is on the aromatic ring. DFT calculations allow the attribution of the experimental IR bands. The solid-state UV-Vis spectrum revealed that this compound exhibits two absorption bands around 330 and $620 \mathrm{~nm}$ mainly due to the cobalt complex.

\section{Supplementary data}

Crystallographic data for the structural analysis have been deposited at the Cambridge Crystallographic Data Centre, CCDC No 2039818. These data can be obtained free of charge via http://www.ccdc.cam.ac.uk/conts/retrieving.html, or from the CCDC, 12 Union Road, Cambridge, CB2 1EZ, UK: fax: (+44) 01223-336-033; e-mail: deposit@ccdc.cam.ac.

\section{References}

[1] H.L. Jia, M.J. Jia, G.H. Li, Y.N. Wang, J.H. Yu, J.Q. Xu, Dalton Trans. 42 (2013) 6429-6439.

[2] R. Jabbar, S. Kamoun, J. Inorg. Organomet. Polym. Mater. 30 (2020) 649-657.

[3] W.Y. Fan, Z.B. Tan, J.I. Koh, Polyhedron 96 (2015) 38-43. 
[4] Y. Wang, D. Wang, W. Shu, J. Sha, H. Zhang, Transit. Met. Chem. 45 (2020) 245251.

[5] Y. Hanifehpour, B. Soltani, B. Mirtamizdoust, B. Khomami, S.W. Joo, J. Inorg. Organomet. Polym. Mater. 26 (2016) 335-343.

[6] J. Mrozinski, J. Klak, R. Kruszynski, Polyhedron. 27 (2008) 1401-1407.

[7] S. Chattopadhyay, K. Bhar, S. Das, S. Chantrapromma, H.K. Fun, B.K. Ghosh, J. Mol. Struct. 967 (2010) 112-118.

[8] Y.P. Quan, P. Yin, N.N. Han, A.H. Yang, H.L Gao, J.Z. Cui, W. Shib, P Cheng, Inorg. Chem. Commun. 12 (2009) 469-472.

[9] L.L. Li, R.X. Yuan, L.L. Liu, Z.G. Ren, A.X. Zheng, H.J. Cheng, H.X. Li, J.P. Lang, Cryst. Growth Des. 10 (2010) 1929-1938.

[10] H. Zhang, X.M. Wang, K. C. Zhang, B.K. Teo, Coord. Chem. Rev. 183 (1999) 157195.

[11] G. Francese, S. Ferlay, H.W. Schmalle, S. Decurtins, New J. Chem. 23 (1999) 267269.

[12] (a) G. De Munno, G. Bruno, F. Nicolo, M. Julve, J.A. Real, Acta Crystallogr., Sect. C 49 (1993) 457; (b) M. Julve, M. Verdaguer, G. De Munno, J.A. Real, G. Bruno, Inorg. Chem. 32 (1993) 795.

[13] J.A.R. Navarro, M.A. Romero, J.M. Salas, M. Quiros, E.R.T. Tiekink, Inorg. Chem. 36 (1997) 4988-4991.

[14] J. Ribas, C. Diaz, X. Solans, M.F. Bardia, Inorg. Chim. Acta 231 (1995) 229.

[15] A. Skorupa, B. Korybut-Daszkiewicz, J. Mrozinski, Inorg. Chim. Acta 324 (2001) 286-292.

[16] H.Z. Kou, D.Z. Liao, P. Cheng, Z.H. Jiang, S.P. Yan, G.L. Wang, X.K. Yao, H.G. Wang, Can. J. Chem. 76 (1998) 1102-1107.

[17] M. C. Burla, B. Chiari, A. Cinti, O. Piovesana, Mol. Cryst. Liq. Cryst. 273 (1995) 211-217.

[18] M.B. Hursthouse, K.J. Izod, M.A. Thornton, Polyhedron 9 (1990) 535-539.

[19] E. Shurdha, C. Moore, A. Rheingold, S. Lapidus, P. Stephens, A. Arif, Miller, Inorg.Chem. 52 (2013) 10583-10594.

[20] K. Kulig, J. Sapa, D. Maciag, B. Filipek, B. Malawska, Arch. Pharm. 340 (2007) 466475 .

[21] A. Pietrzycka, M. Stepniewski, A.M. Waszkielewicz, H. Marona, Acta Pol. Pharm. 63 (2006) 19-24. 
[22] R. Kharb, K. Bansal, A.K. Sharma, Der Pharma Chem. 4 (2012) 2470-2488.

[23] A. K. Rathi, R. Syed,Han-Seung Shin, R. V. Patel ( 2016) 777-797.

[24] R. Jabbar, F. Michaud, S. Kamoun, Chemical Papers. 73 (2019) 1389-1399.

[25] S.C. Manna, A.D. Jana, M.G.B. Drew, G. Mostafa, N. R. Chaudhuri, Polydedron 27 (2008) 1280-1286.

[26] J. Palion-Gazda, B. Machura, R. Kruszynski, T. Grancha, N. Moliner, F. Lloret, M. Julve, Inorg. Chem. 56 (2017) 6281-6296.

[27] Y.Y. Zhu, F. Liu, J.J. Liu, Y.S. Meng, S.D. Jiang, A.L. Barra, W. Wernsdorfer, S. Gao, Inorg. Chem. 56 (2017) 697-700.

[28] P.Sobczak, A. Barasinski, A. Drzewinski , G. Kamieniarz , J. Kłak, A. Bienko, J. Mrozinski, Polyhedron 28 (2009) 1838-1841.

[29] CrystalClear: Data Collection and Processing Software, Rigaku Corporation, Tokyo 196-8666, Japan (1998-2014).

[30] G.M. Sheldrick. Acta Cryst., A64, 112 (2008).

[31] G.M. Sheldrick. Acta Cryst., C71, 3 (2015).

[32] CrystalStructure 4.1: Crystal Structure Analysis Package, Rigaku Corporation, Tokyo 196-8666, Japan (2000-2014).

[33] K. Brandenburg, Diamond Version 2.0 Impact GbR, Bonn, Germany (1998).

[34] J.J. McKinnon, D. Jayatilaka, M.A. Spackman, Chem. Commun. 37 (2007) 3814-3816.

[35] C. Jelsch, S. Soudani, C. Ben Nasr, IUCr J. 2 (2015) 327-340.

[36] B. Guillot, E. Enrique, L. Huder, C. Jelsch, MoProViewer, Acta Cryst., A70 (2014) 279.

[37] R. Rabelo, A.K. Valdo, C. Robertson, J. A. Thomas, H. O. Stumpf, F. T. Martins, E. F. Pedroso, M. Julve, F. Llorete, D. Cangussu, New J. Chem. 41 (2017) 6911-6921.

[38] X. Chen, S.L. Dai, Z.P. Cheng, L.B. Liang, S. Han, J.F Liu, J.R. Zhou, L.M. Yang, C.L. Ni, Synth. React. Inorg. Met. Org. Nano Met. Chem. 42 (2012) 987-993.

[39] W.Q Chen, L.J Su, X.Q Cai, J.J. Yang, Y.L. Qian, X.P. Liu, L.M Yang, J.R. Zhou, C.L Ni, Synth. React. Inorg. Met. Org. Nano Met. Chem. 44 (2014) 980-985.

[40] H.Q. Ye, L.J. Su, X.X. Chen, X. Liao, Q.T. Liu, X.Y. Wu, J.R. Zhou, L.M. Yang, C.L Ni, Synth. Met. 199 (2015) 232-240.

[41] H.Q. Ye, J.L. Xie, J.Y. Yu, Q.T Liu, S.L. Dai, W.Q. Huang, J.R. Zhou, L.M. Yang, C.L Ni, Synth. Met. 197 (2014) 99-104.

[42] H.Q. Ye, Y.Y Li, R.K. Huang, X.P. Liu, W.Q. Chen, J.R. Zhou, L.M. Yang, C.L Ni, J. Struct. Chem. 55 (2014) 691-696.

[43] A. Hannachi, A. Valkonen, M. Rzaigui, W. Smirani, Polyhedron. 161 (2019) 222-230. 
[44] Z. Zhang, J. Xu, S. Yan, Y. Chen, Y. Wang, Z. Chen, CL Ni, Crystals 7 (2017) 92105.

[45] H. J. Chen, L. Z. Zhang, Z.G. Cai, G. Yang, X. M. Chen, J. Chem. Soc. Dalton Trans. 14 (2000) 2463-2466.

[46] X. Chen, W.Q. Chen, S. Han, J.F. Liu, J.R. Zhou, L.L. Yu, J. Mol. Struct. 984 (2010) 164-169.

[47] K. S. Saikat, B. Seth, K. Tanusree, J. Mol. Struct. 965 (2010) 45-49.

[48] K.S. Saikat, C.S. Nitish, G. Soumen, K. Tanusree, Chem. Phys. Lett. 506 (2011) 309314.

[49] E.M. Rakhmanko, Y.V. Matveichuk, V.V. Yasinetskii, J. Anal. Chem. 70 (2015) 178185.

[50] H.T. Cai, Q.T. Liu, H.Q. Ye, L.J. Su, X.X. Zheng, J.N. Li, S.H. Ou, J.R. Zhou, L. M Yang, C.L. Ni, Spectrochim. Acta A Mol. Biomol. Spectrosc. 142 (2015) 239-245.

[51] G. M. Ionita, G. Ilie, C. Angel, F. Dan, D. K. Smith, V. Chechik, Langmuir 29 (2013) 9173-9178.

[52] S. J. Osborne, S. Wellens, C. Ward, S. Felton, R.M. Bowman, K. B Binnemans, M. Swad_zba-Kwa_sny, H. Q. N. Gunaratne, P. Nockemann, Dalton Trans. 44 (2015) 11286-11289.

[53] A. A. Bagabas, M. Alsawalha, M. Sohail, S. Alhoshan, R. Arasheed, Heliyon 5 (2019) e01139

[54] Z. Kantarci, M. Karabacak, M. M. Bülbül, J. Incl. Phenom. Macro. 40 (2001) 317321. 


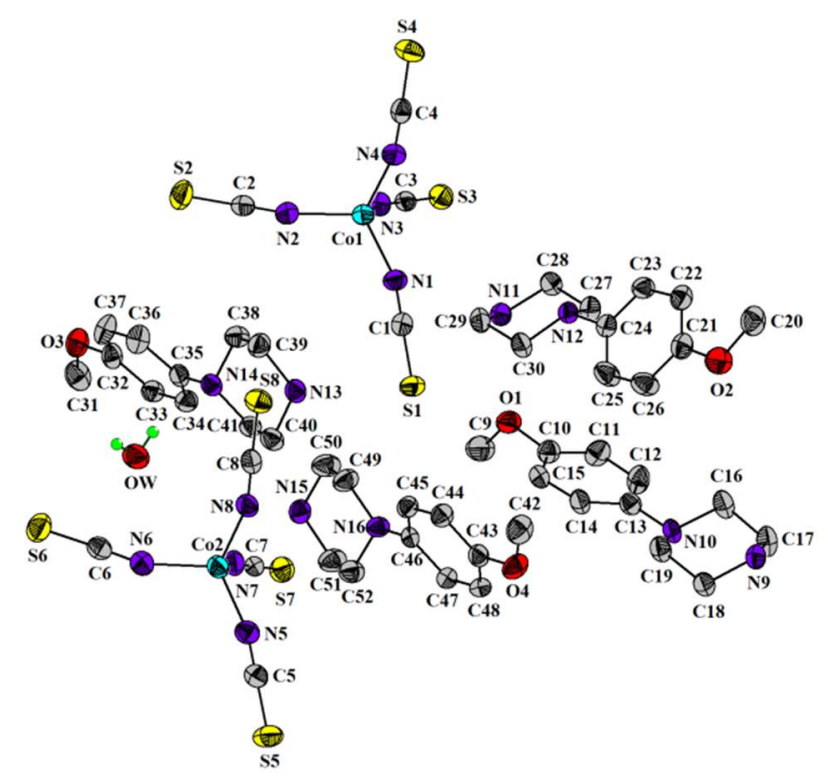

Fig. 1. ORTEP of $[1-4 \mathrm{MPPip}]_{4}\left[\mathrm{Co}(\mathrm{NCS})_{4}\right]_{2} \cdot \mathrm{H}_{2} \mathrm{O}$ with displacement ellipsoids drawn at the $40 \%$ probability level.

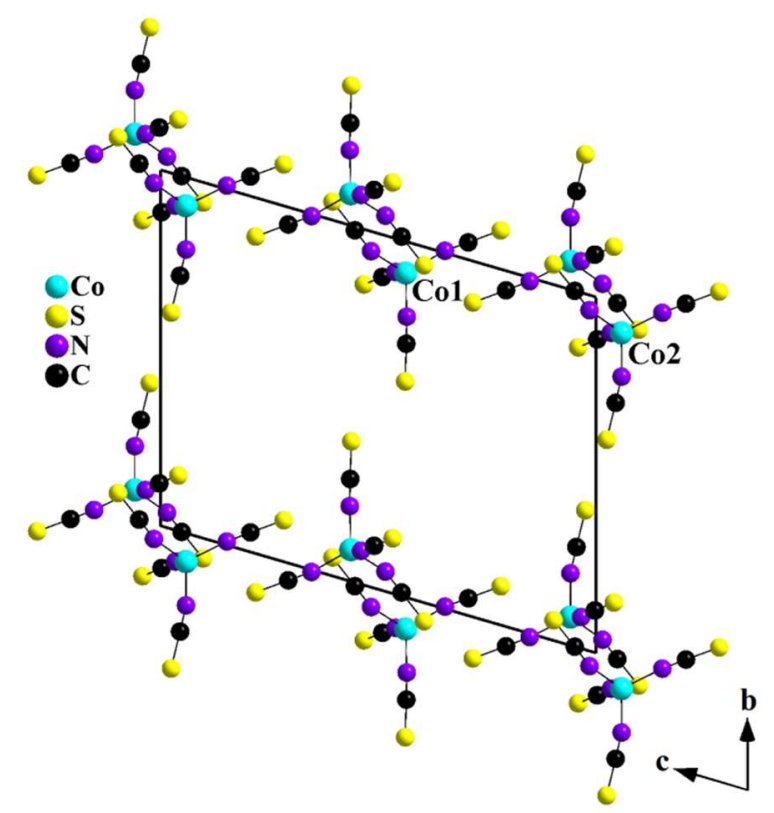

Fig. 2. Projection along the $a$-axis the cobalt complexes in [1-4MPPip $]_{4}\left[\mathrm{Co}(\mathrm{NCS})_{4}\right]_{2} \cdot \mathrm{H}_{2} \mathrm{O}$. 


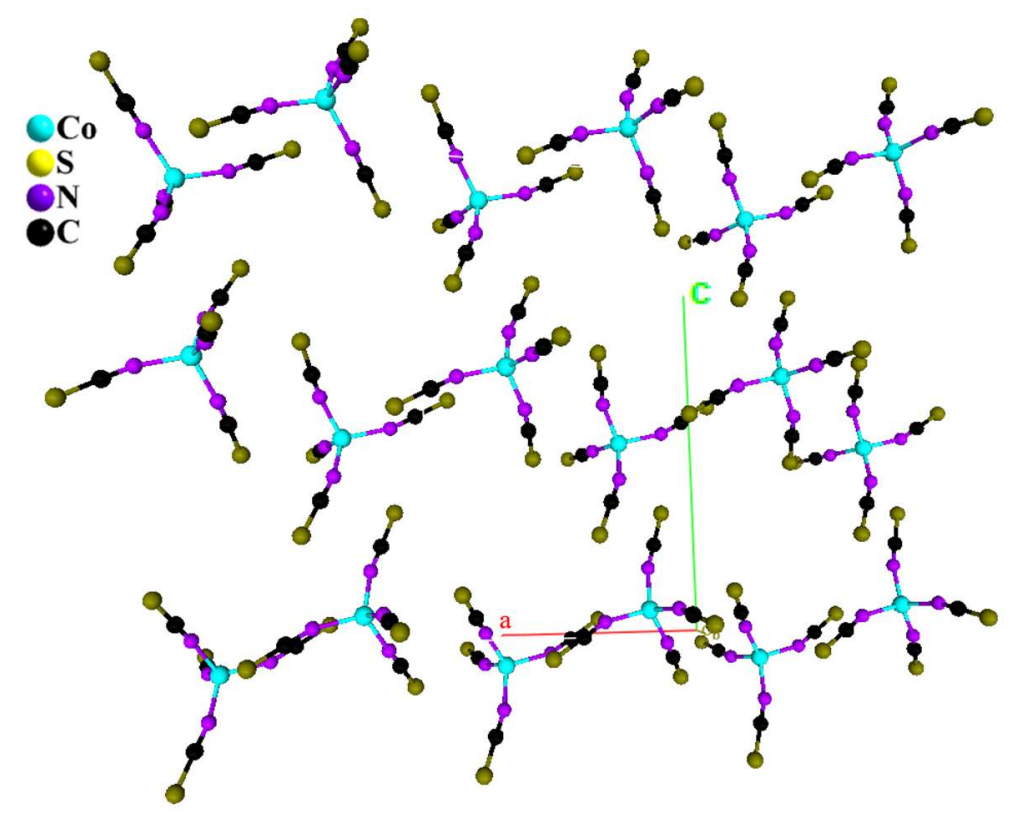

Fig. 3. Crystallographic autostereogram showing the $\mathrm{Co}(\mathrm{SCN})_{4}$ moieties forming a layer parallel to the $(a, c)$ plane in [1-4MPPip $]_{4}\left[\mathrm{Co}(\mathrm{NCS})_{4}\right]_{2} \cdot \mathrm{H}_{2} \mathrm{O}$.

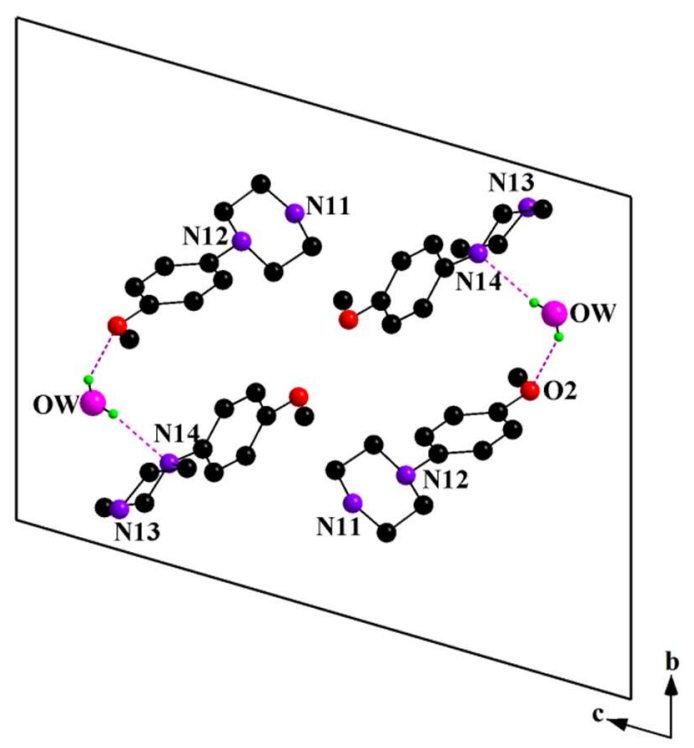

Fig. 4. Projection along the $a$-axis the associated organic entities, via water molecules, in [14MPPip $]_{4}\left[\mathrm{Co}(\mathrm{NCS})_{4}\right]_{2} \cdot \mathrm{H}_{2} \mathrm{O}$ 


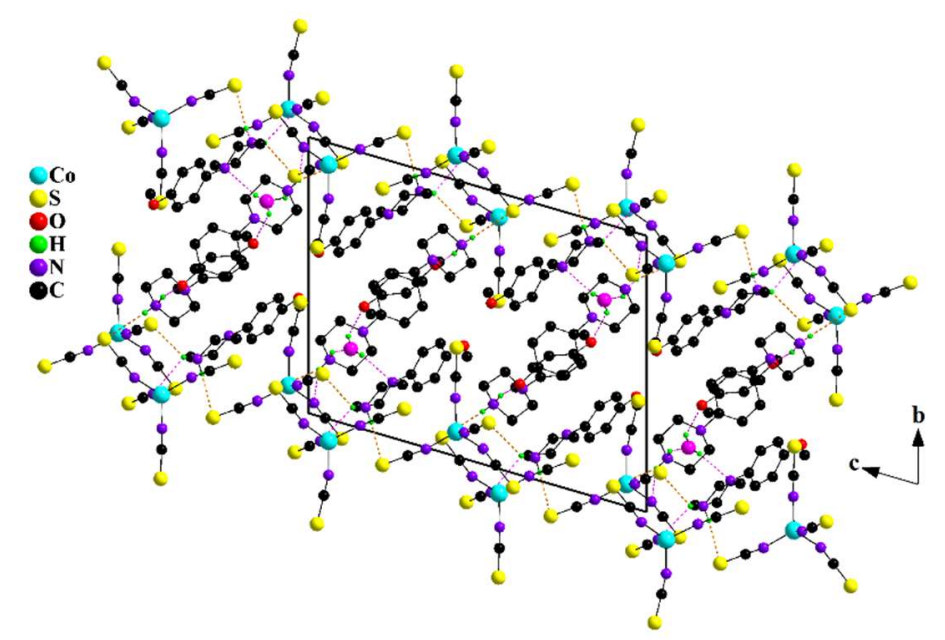

Fig. 5. Projection along the $a$-axis of the structure of $[1-4 \mathrm{MPPip}]_{4}\left[\mathrm{Co}(\mathrm{NCS})_{4}\right]_{2} \cdot \mathrm{H}_{2} \mathrm{O}$.

Dotted lines indicate hydrogen bonds.

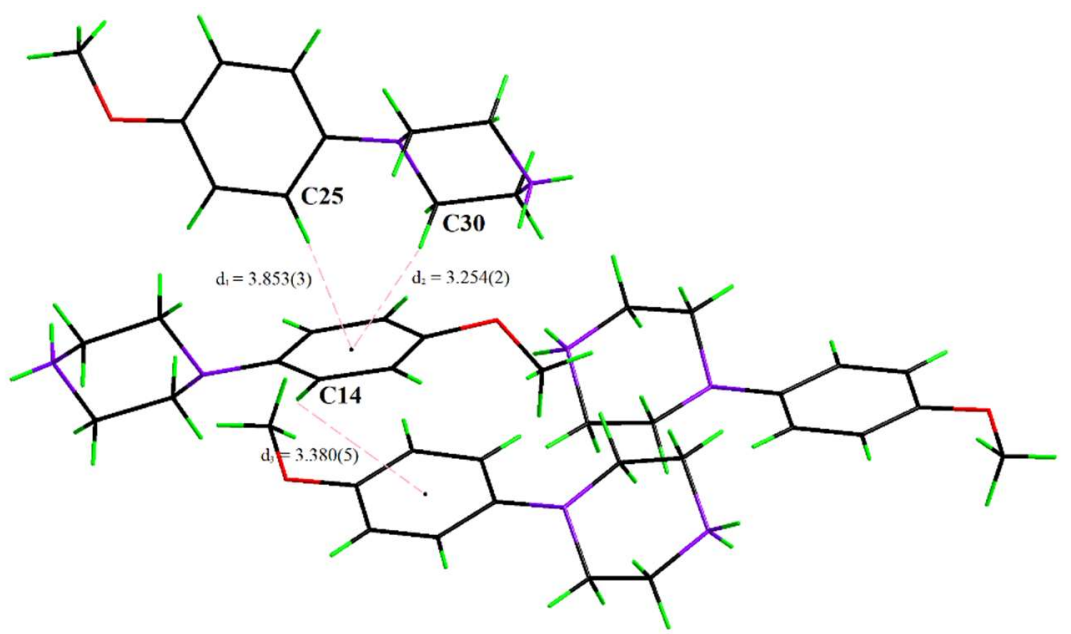

Fig. 6. Intermolecular interactions $\mathrm{C}-\mathrm{H} . . . \pi$ between hydrogen atoms and the neighboring aromatic rings in $[1-4 \mathrm{MPPip}]_{4}\left[\mathrm{Co}(\mathrm{NCS})_{4}\right]_{2} \cdot \mathrm{H}_{2} \mathrm{O}$. 


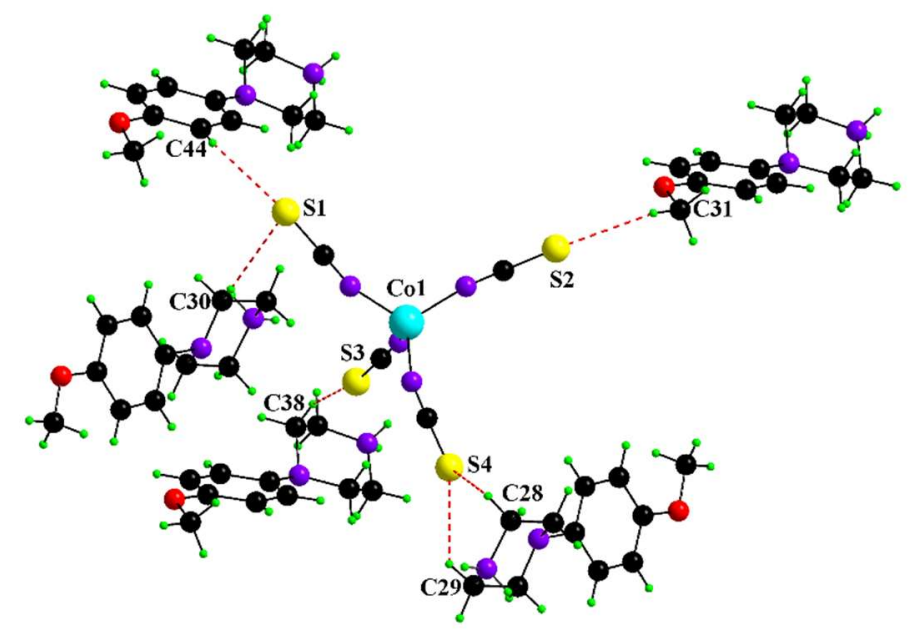

(a)

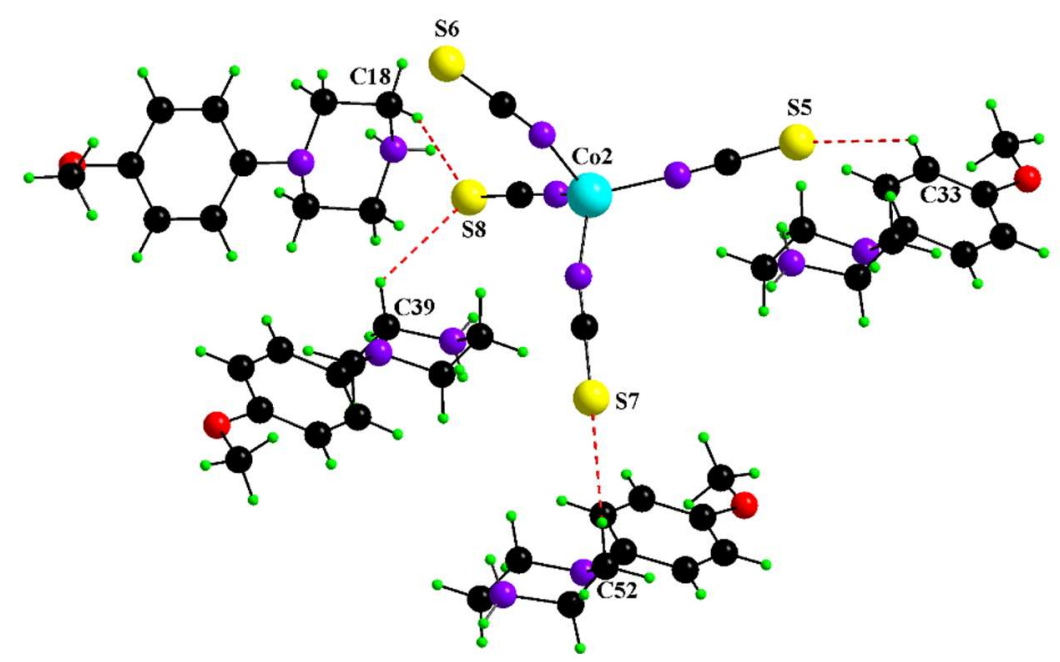

(b)

Fig. 7. Intermolecular interactions C-H...S between hydrogen atoms and the sulfur atoms of the $\mathrm{Co} 1$ (a) and $\mathrm{Co} 2$ (b) cobalt atoms in [1-4MPPip $]_{4}\left[\mathrm{Co}(\mathrm{NCS})_{4}\right]_{2} \cdot \mathrm{H}_{2} \mathrm{O}$ (a). 


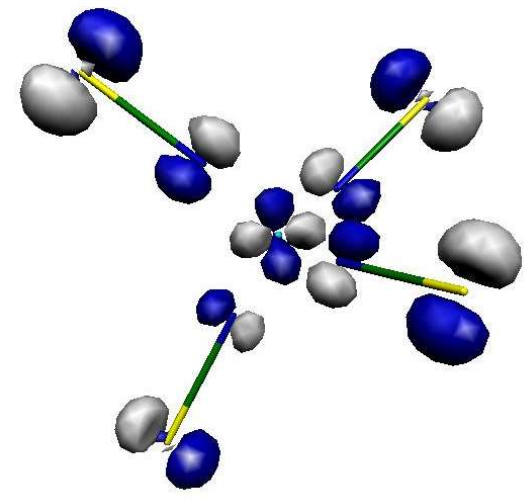

HOMO

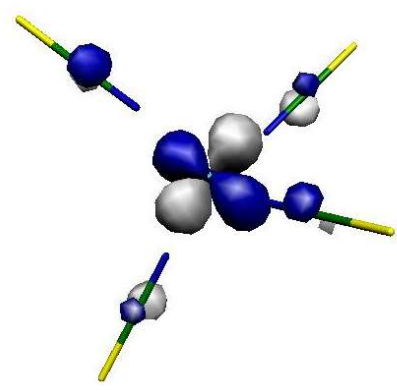

LUMO

(a)

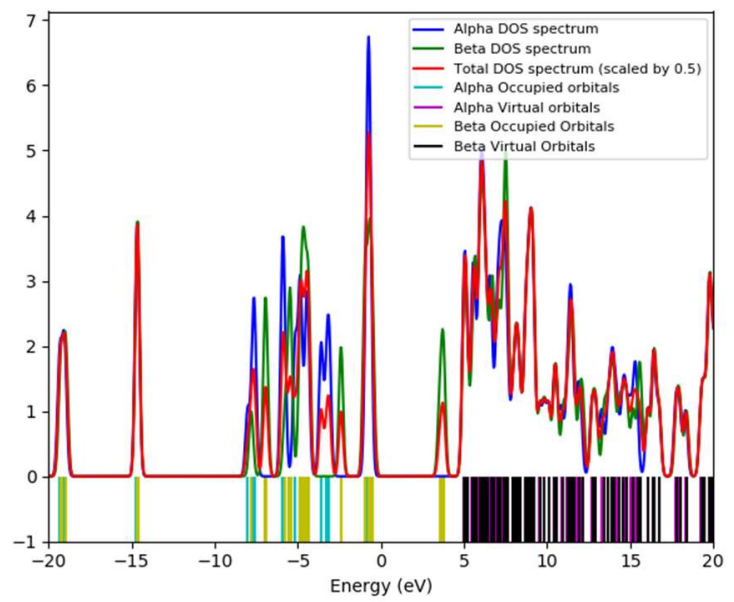

(b)

Fig. 8. Frontier orbitals of the anionic entity (a). Energy distribution of the different orbitals of an anionic entity. The two cobalt complexes give similar result (b). 


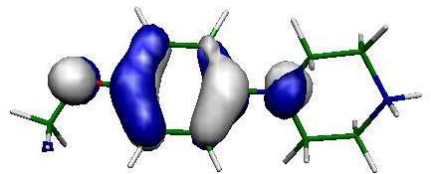

HOMO

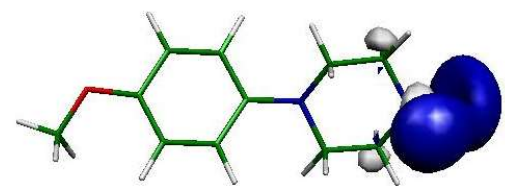

LUMO

(a)

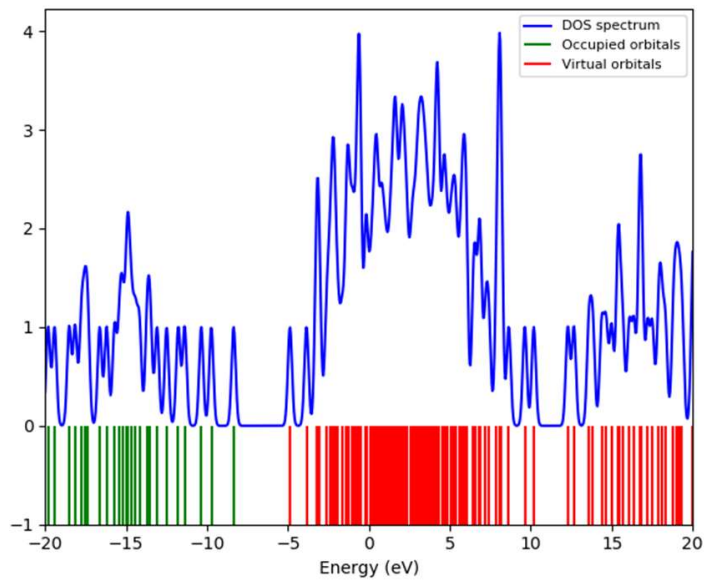

(b)

Fig. 9. Frontier orbitals of the organic entity (a). Energy distribution of the different orbitals of an organic entity. The four ligands give similar results (b). 


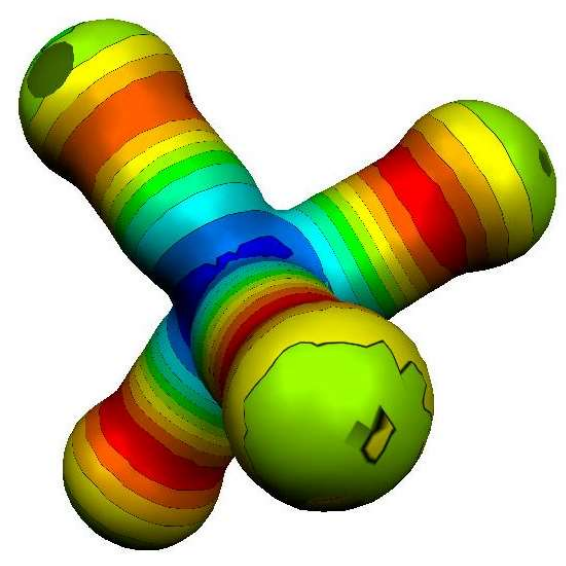

(a)

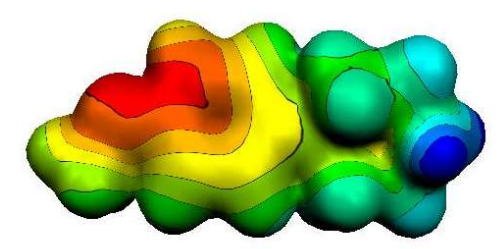

(b)

Fig. 10. Molecular Electrostatic Potential maps of the anionic entity (a). Molecular Electrostatic Potential maps of the organic entity (b). 
(a)

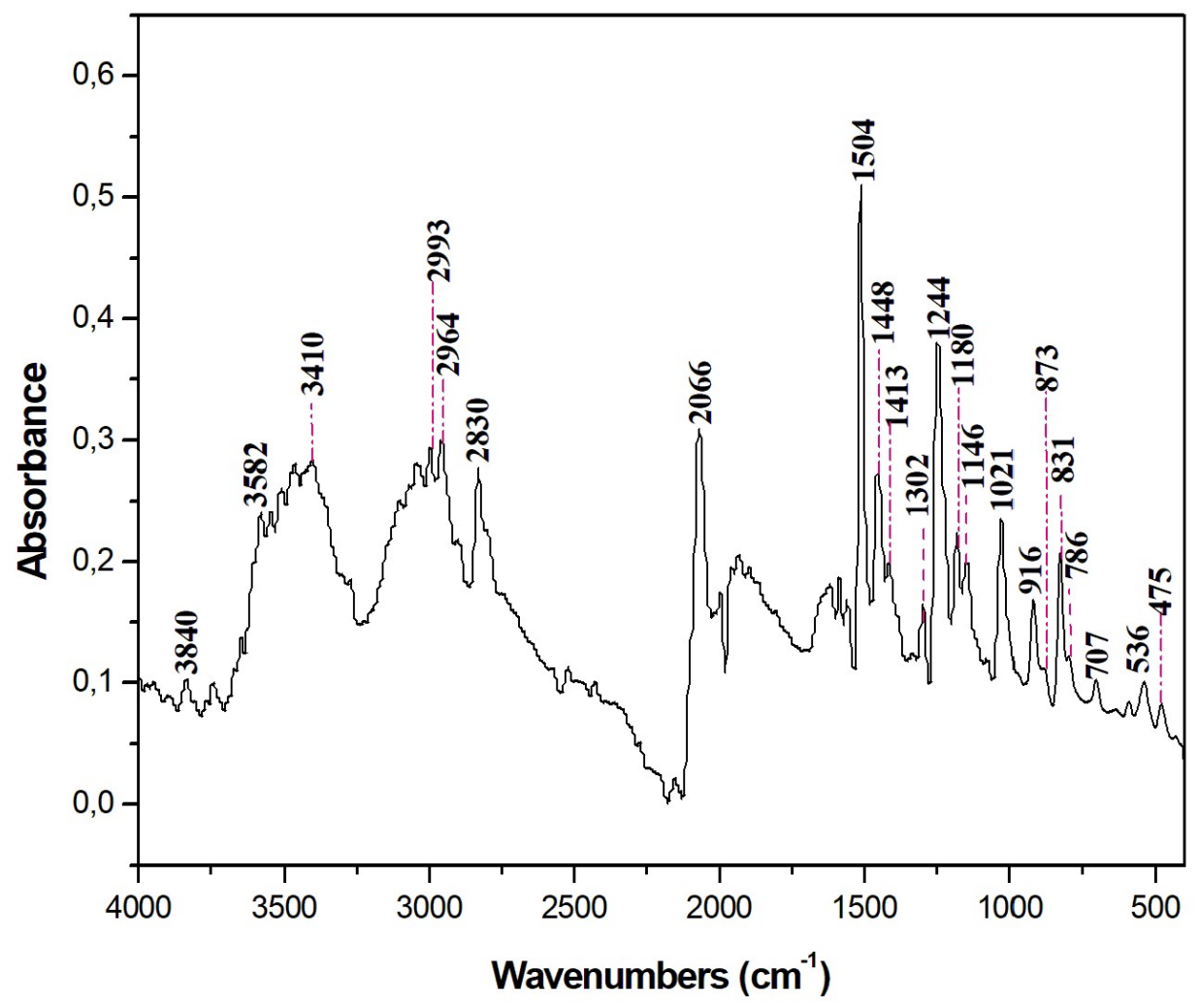

(b)

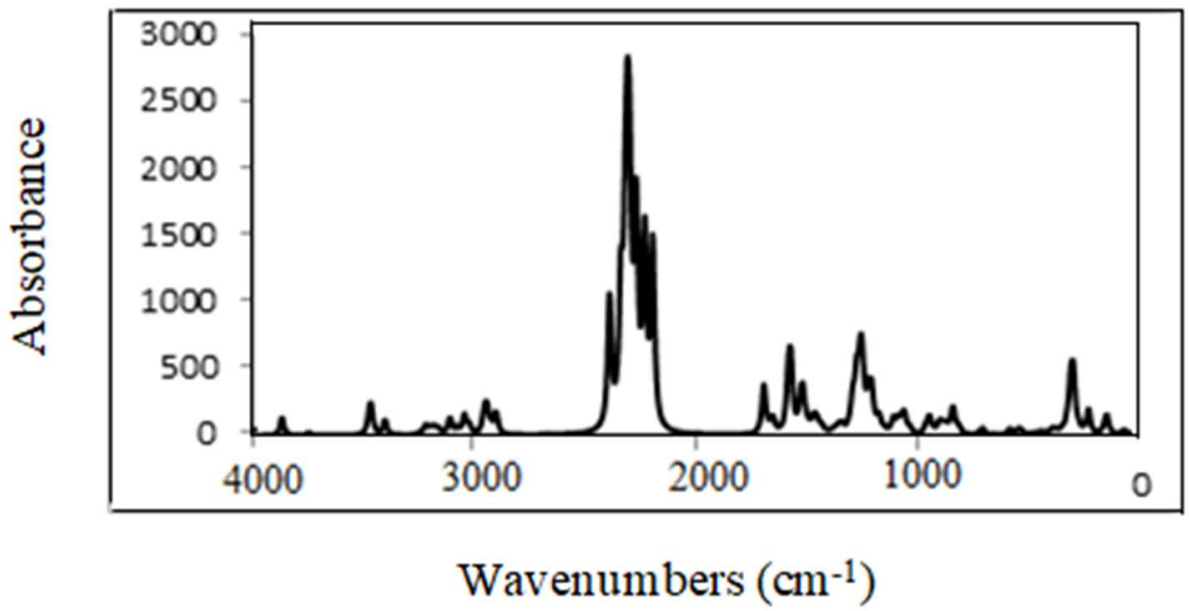

Fig. 11. Infrared absorption spectra of $[1-4 \mathrm{MPPip}]_{4}\left[\mathrm{Co}(\mathrm{NCS})_{4}\right]_{2} \cdot \mathrm{H}_{2} \mathrm{O}$.

(a) Experimental and (b) Theoretical. 


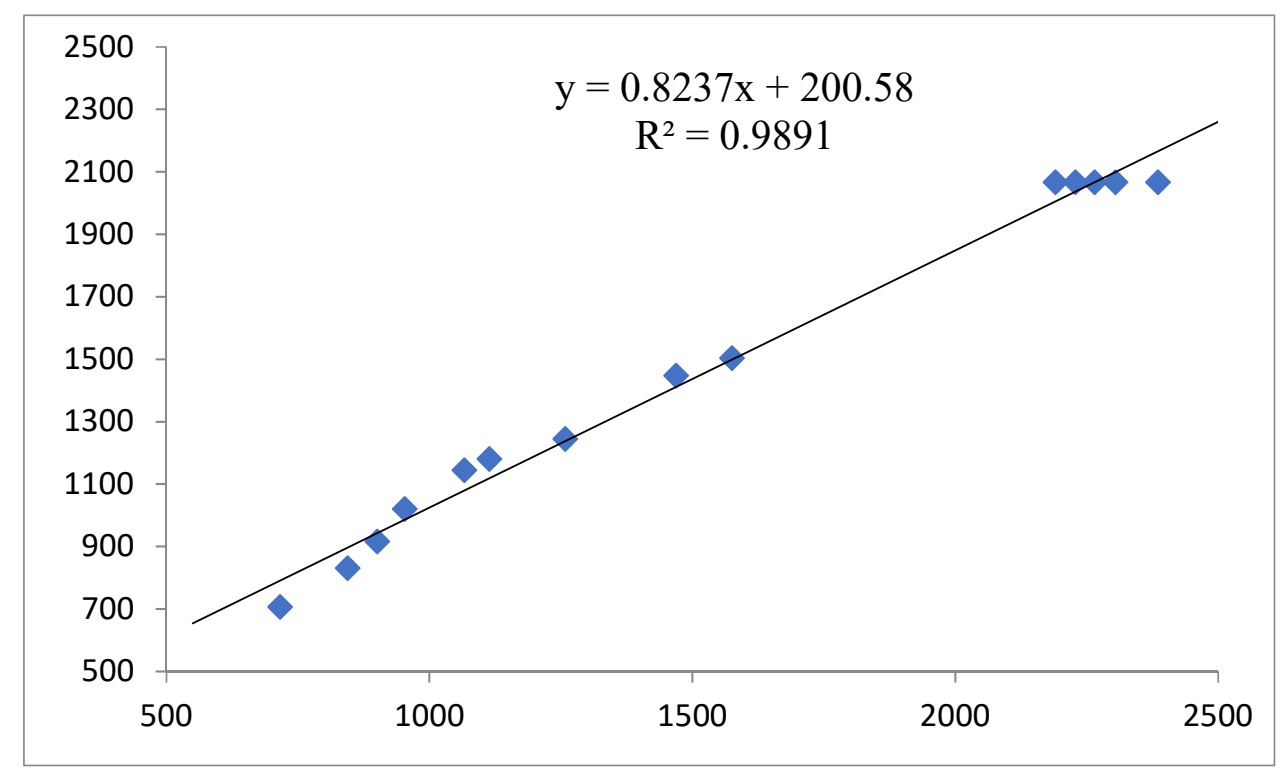

Fig. 12. Comparison between experimental and calculated IR frequencies of [14MPPip $]_{4}\left[\mathrm{Co}(\mathrm{NCS})_{4}\right]_{2} \cdot \mathrm{H}_{2} \mathrm{O}$.

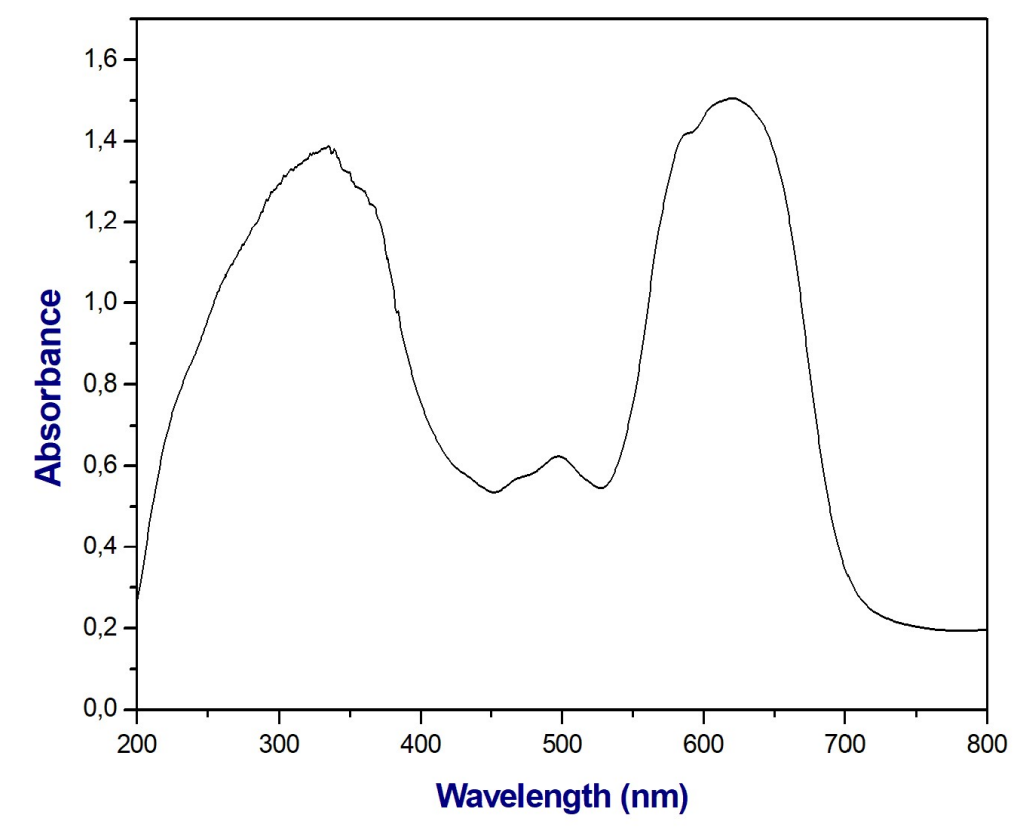

Fig. 13. Solid state UV-Vis spectrum of $\left(\mathrm{C}_{11} \mathrm{H}_{17} \mathrm{~N}_{2} \mathrm{O}\right)_{4}\left[\mathrm{Co}(\mathrm{NCS})_{4}\right]_{2} \cdot \mathrm{H}_{2} \mathrm{O}$. 


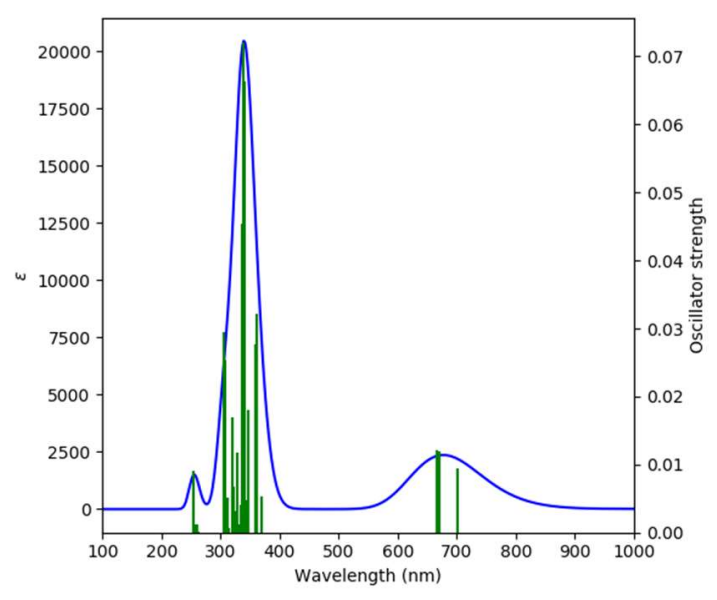

Fig. 14. Calculated UV-Vis spectrum of the anionic complex in $\left(\mathrm{C}_{11} \mathrm{H}_{17} \mathrm{~N}_{2} \mathrm{O}\right)_{4}\left[\mathrm{Co}(\mathrm{NCS})_{4}\right]_{2} \cdot \mathrm{H}_{2} \mathrm{O}$.

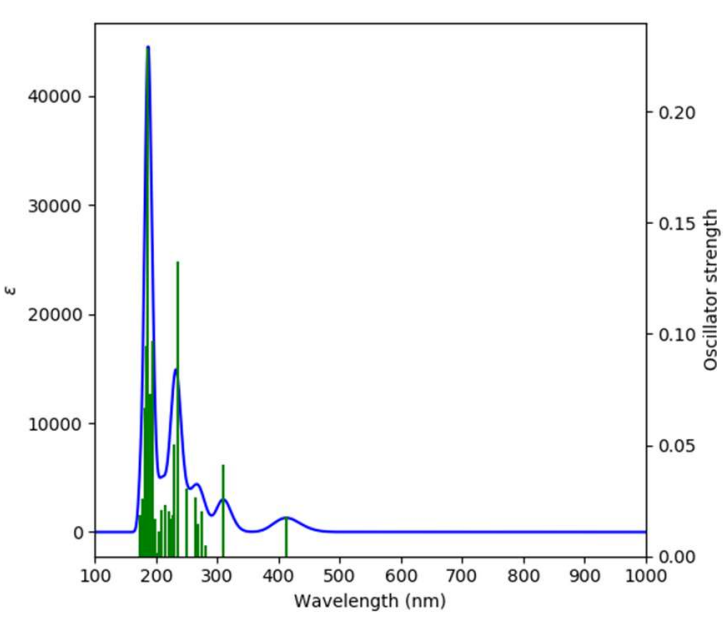

Fig. 15. Calculated UVVis spectrum of the organic cation in

$\left(\mathrm{C}_{11} \mathrm{H}_{17} \mathrm{~N}_{2} \mathrm{O}\right)_{4}\left[\mathrm{Co}(\mathrm{NCS})_{4}\right]_{2} \cdot \mathrm{H}_{2} \mathrm{O}$.

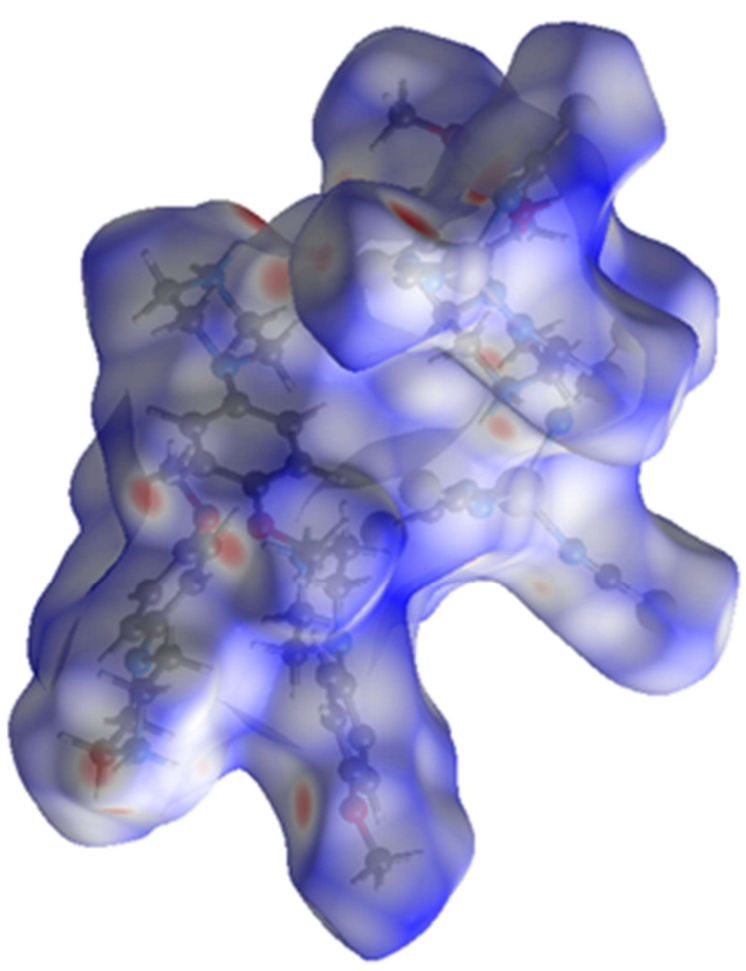

Fig. 16. View of the $d_{\text {norm }}$ quantity mapped on the Hirshfeld surface of the asymmetric unit of the title compound. The red color represents the area on the surfaces where the atoms make intermolecular contacts closer than the sum of their Van der Waals radii. 

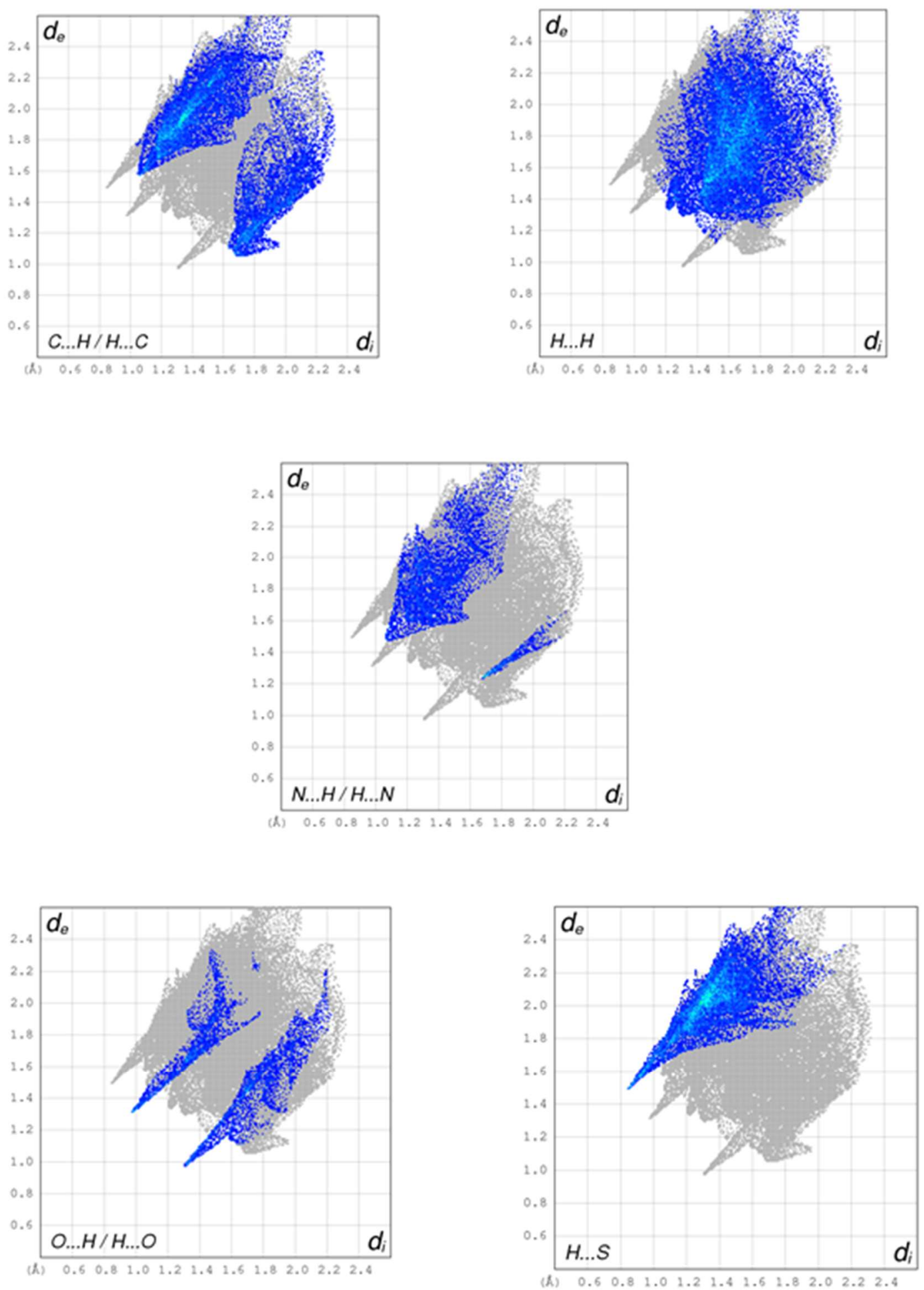

Fig. 17. Fingerprint plots of the main contact around the organic cation 1-(4methoxyphenyl)piperazinium (containing O15). 


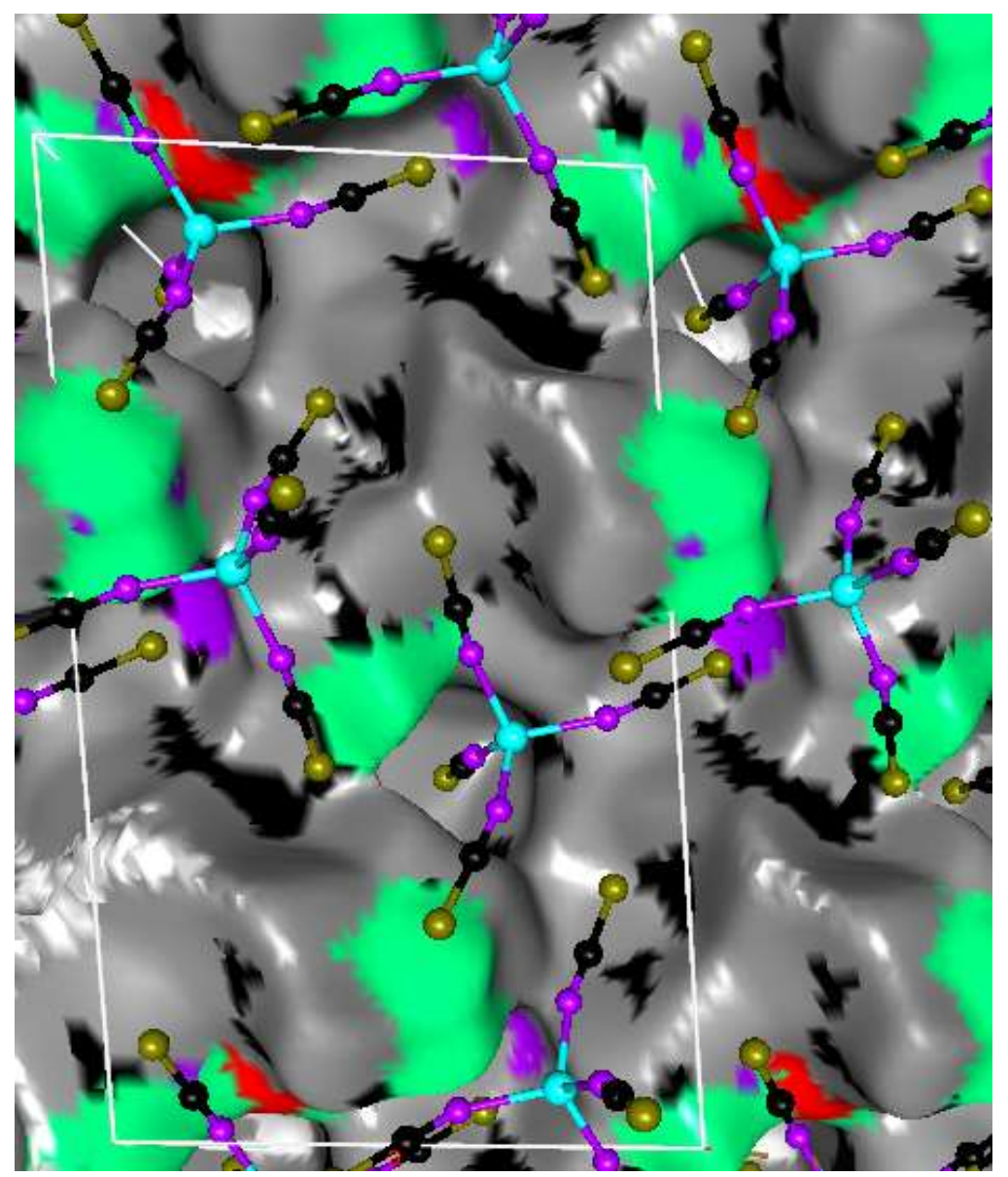

Fig. 18. Crystallographic autostereogram showing the $\mathrm{Co}(\mathrm{SCN})_{4}$ moieties forming a layer parallel to the $(a, c)$ plane. The surface is colored according to the atom type on the organic cation + water side. C: black, Hc: grey, Ho/n: green, O: red, N: purple, S: yellow. 
Table 1: Crystallographic data and structure refinement for [1-4MPPip $]_{4}\left[\mathrm{Co}(\mathrm{NCS})_{4}\right]_{2} \cdot \mathrm{H}_{2} \mathrm{O}$

\section{Data Crystal}

\begin{tabular}{lll}
\hline Chemical formula & $\left(\mathrm{C}_{11} \mathrm{H}_{17} \mathrm{~N}_{2} \mathrm{O}\right)_{4}\left[\mathrm{C}_{4} \mathrm{CoN}_{4} \mathrm{~S}_{4}\right]_{2} \cdot \mathrm{H}_{2} \mathrm{O}$ & \\
Formula weight $\left(\mathrm{g} \cdot \mathrm{mol}^{-1}\right)$ & 1373.58 & \\
Temperature $(\mathrm{K})$ & 150 & \\
Crystal System & Triclinic & \\
Space group & $\mathrm{P} \overline{1}$ & $\alpha=72.754(16)^{\circ}$ \\
Unit cell dimensions & $a=11.497(5) \AA$ & $\beta=84.23(2)^{\circ}$ \\
& $b=16.155(7) \AA$ & \\
& $c=19.3921(10) \AA$ & \\
$Z$ & 2 & \\
Cell volume $\left(\AA^{3}\right)$ & $3224(2)$ & \\
Absorption coefficient $\mu\left(\mathrm{mm}^{-1}\right)$ & 0.83 & \\
crystal dimensions $\left(\mathrm{mm}^{3}\right)$ & $0.4 \times 0.3 \times 0.25$ & \\
Color, shape & Blue, Prism
\end{tabular}

\section{Data collection}

Diffractometer

$\theta$ range $\left(^{\circ}\right)$

Index range $(\mathrm{h}, \mathrm{k}, \mathrm{l})$

No. of measured, independent and observed with $I>2 \sigma(I)$ reflections
Rigaku Mercury70

$\theta_{\min }=3.0^{\circ}, \theta_{\max }=27.5^{\circ}$

$h=-14 \rightarrow 14, k=-20 \rightarrow 20, l=-25 \rightarrow 25$

$37861,14659,10293$

0.061

$T_{\min }=0.702, T_{\max }=0.822$

$\operatorname{Mo}\left(\mathrm{K}_{\alpha}\right) \quad \lambda(\AA)=0.71073$

Radiation type

\section{Refinement parameters}

$R, w R^{2} \quad 0.081,0.225$

Goodness-of-fit on $F^{2} \quad 1.14$

$\Delta \rho_{\max }, \Delta \rho_{\min }\left(\mathrm{e} \AA^{-3}\right) \quad 1.14,-0.79$ 
Table 2. Selected bond lengths and bond angles of the two cobalt complexes in the title compound.

\begin{tabular}{|c|c|c|c|}
\hline \multicolumn{4}{|l|}{ Bond length $(\AA)$} \\
\hline Co1(NCS) 4 & & $\mathrm{Co} 2(\mathrm{NCS}) 4$ & \\
\hline $\mathrm{Co} 1-\mathrm{N} 2$ & $1.949(4)$ & $\mathrm{Co} 2-\mathrm{N} 6$ & $1.946(4)$ \\
\hline $\mathrm{Co} 1-\mathrm{N} 1$ & $1.950(4)$ & $\mathrm{Co} 2-\mathrm{N} 5$ & $1.959(4)$ \\
\hline Co1-N4 & $1.957(4)$ & $\mathrm{Co} 2-\mathrm{N} 7$ & $1.964(4)$ \\
\hline $\mathrm{Co} 1-\mathrm{N} 3$ & $1.967(4)$ & $\mathrm{Co} 2-\mathrm{N} 8$ & $1.974(4)$ \\
\hline $\mathrm{S} 3-\mathrm{C} 3$ & $1.614(5)$ & S7-C7 & $1.621(5)$ \\
\hline $\mathrm{S} 1-\mathrm{C} 1$ & $1.625(5)$ & $\mathrm{S} 8-\mathrm{C} 8$ & $1.608(5)$ \\
\hline $\mathrm{S} 4-\mathrm{C} 4$ & $1.610(5)$ & $\mathrm{S} 5-\mathrm{C} 5$ & $1.618(5)$ \\
\hline $\mathrm{S} 2-\mathrm{C} 2$ & $1.618(5)$ & $\mathrm{S} 6-\mathrm{C} 6$ & $1.623(5)$ \\
\hline $\mathrm{N} 1-\mathrm{C} 1$ & $1.159(5)$ & $\mathrm{N} 8-\mathrm{C} 8$ & $1.170(6)$ \\
\hline $\mathrm{N} 4-\mathrm{C} 4$ & $1.180(6)$ & $\mathrm{N} 5-\mathrm{C} 5$ & $1.161(6)$ \\
\hline $\mathrm{N} 2-\mathrm{C} 2$ & $1.164(6)$ & $\mathrm{N} 7-\mathrm{C} 7$ & $1.165(6)$ \\
\hline $\mathrm{N} 3-\mathrm{C} 3$ & $1.174(6)$ & $\mathrm{N} 6-\mathrm{C} 6$ & $1.152(6)$ \\
\hline \multicolumn{4}{|l|}{ Bond angles $\left(^{\circ}\right)$} \\
\hline $\mathrm{N} 2-\mathrm{Co} 1-\mathrm{N} 1$ & $113.12(16)$ & $\mathrm{N} 6-\mathrm{Co} 2-\mathrm{N} 5$ & $111.80(17)$ \\
\hline $\mathrm{N} 2-\mathrm{Co} 1-\mathrm{N} 4$ & $108.98(17)$ & $\mathrm{N} 6-\mathrm{Co} 2-\mathrm{N} 7$ & $108.64(17)$ \\
\hline $\mathrm{N} 1-\mathrm{Co} 1-\mathrm{N} 4$ & $110.36(16)$ & $\mathrm{N} 5-\mathrm{Co} 2-\mathrm{N} 7$ & $108.79(17)$ \\
\hline $\mathrm{N} 2-\mathrm{Co} 1-\mathrm{N} 3$ & $108.89(16)$ & $\mathrm{N} 6-\mathrm{Co} 2-\mathrm{N} 8$ & $106.13(17)$ \\
\hline $\mathrm{N} 1-\mathrm{Co} 1-\mathrm{N} 3$ & $109.29(16)$ & $\mathrm{N} 5-\mathrm{Co} 2-\mathrm{N} 8$ & $110.36(16)$ \\
\hline $\mathrm{N} 4-\mathrm{Co} 1-\mathrm{N} 3$ & $105.94(16)$ & $\mathrm{N} 7-\mathrm{Co} 2-\mathrm{N} 8$ & $111.11(16)$ \\
\hline $\mathrm{C} 1-\mathrm{N} 1-\mathrm{Co} 1$ & $162.2(4)$ & $\mathrm{C} 8-\mathrm{N} 8-\mathrm{Co} 2$ & $157.7(4)$ \\
\hline $\mathrm{C} 4-\mathrm{N} 4-\mathrm{Co} 1$ & $160.3(4)$ & $\mathrm{C} 5-\mathrm{N} 5-\mathrm{Co} 2$ & $165.6(4)$ \\
\hline $\mathrm{C} 2-\mathrm{N} 2-\mathrm{Co} 1$ & $169.4(4)$ & $\mathrm{C} 7-\mathrm{N} 7-\mathrm{Co} 2$ & $164.1(4)$ \\
\hline $\mathrm{C} 3-\mathrm{N} 3-\mathrm{Co} 1$ & $158.5(4)$ & $\mathrm{C} 6-\mathrm{N} 6-\mathrm{Co} 2$ & $163.3(4)$ \\
\hline $\mathrm{N} 1-\mathrm{C} 1-\mathrm{S} 1$ & $179.4(5)$ & $\mathrm{N} 8-\mathrm{C} 8-\mathrm{S} 8$ & $178.6(4)$ \\
\hline $\mathrm{N} 3-\mathrm{C} 3-\mathrm{S} 3$ & $179.4(4)$ & $\mathrm{N} 7-\mathrm{C} 7-\mathrm{S} 7$ & $178.7(4)$ \\
\hline $\mathrm{N} 2-\mathrm{C} 2-\mathrm{S} 2$ & $178.8(5)$ & $\mathrm{N} 6-\mathrm{C} 6-\mathrm{S} 6$ & $178.3(5)$ \\
\hline $\mathrm{N} 4-\mathrm{C} 4-\mathrm{S} 4$ & $178.5(5)$ & $\mathrm{N} 5-\mathrm{C} 5-\mathrm{S} 5$ & $178.6(4)$ \\
\hline
\end{tabular}


Table 3. Selected hydrogen bonds $\left(\AA,^{\circ}\right)$ parameters.

\begin{tabular}{lllll}
\hline$D-\mathrm{H} \cdots A$ & $D-\mathrm{H}$ & $\mathrm{H} \cdots A$ & $D \cdots A$ & $D-\mathrm{H} \cdots A$ \\
\hline $\mathrm{OW}-\mathrm{H} 1 \cdots \mathrm{N} 14$ & $0.80(1)$ & $2.31(2)$ & $3.071(5)$ & $160(5)$ \\
$\mathrm{OW}-\mathrm{H} 2 \cdots \mathrm{O} 2^{\mathrm{i}}$ & $0.80(1)$ & $2.41(3)$ & $3.104(5)$ & $146(4)$ \\
$\mathrm{N} 9-\mathrm{H} 3 \cdots \mathrm{O} 12^{\mathrm{ii}}$ & $0.92(5)$ & $2.07(5)$ & $2.917(5)$ & $152(4)$ \\
$\mathrm{N} 9-\mathrm{H} 4 \cdots \mathrm{S} 7^{\mathrm{iii}}$ & $0.84(5)$ & $2.74(5)$ & $3.481(5)$ & $148(4)$ \\
$\mathrm{N} 9-\mathrm{H} 4 \cdots \mathrm{N} 7^{\mathrm{ii}}$ & $0.84(5)$ & $2.55(5)$ & $3.126(5)$ & $127(4)$ \\
$\mathrm{N} 11-\mathrm{H} 5 \cdots \mathrm{O} 1$ & $0.98(5)$ & $1.90(5)$ & $2.860(5)$ & $168(4)$ \\
$\mathrm{N} 11-\mathrm{H} 6 \cdots \mathrm{S} 3$ & $0.77(5)$ & $2.85(5)$ & $3.453(4)$ & $136(5)$ \\
$\mathrm{N} 15-\mathrm{H} 9 \cdots \mathrm{S} 5^{\mathrm{iv}}$ & $0.86(5)$ & $2.50(5)$ & $3.361(5)$ & $176(5)$ \\
$\mathrm{N} 15-\mathrm{H} 10 \cdots \mathrm{S} 4{ }^{\mathrm{v}}$ & $0.86(5)$ & $2.60(5)$ & $3.327(5)$ & $142(4)$ \\
$\mathrm{N} 15-\mathrm{H} 10 \cdots \mathrm{N} 4{ }^{\mathrm{vi}}$ & $0.86(5)$ & $2.65(5)$ & $3.183(5)$ & $122(4)$ \\
$\mathrm{N} 13-\mathrm{H} 7 \cdots \mathrm{S} 1$ & $0.87(5)$ & $2.45(5)$ & $3.304(5)$ & $170(5)$ \\
$\mathrm{N} 13-\mathrm{H} 8 \cdots \mathrm{S} 8$ & $0.82(5)$ & $2.72(5)$ & $3.369(4)$ & $138(4)$ \\
$\mathrm{N} 13-\mathrm{H} 8 \cdots \mathrm{N} 8^{\text {vii }}$ & $0.82(5)$ & $2.59(5)$ & $3.183(5)$ & $131(4)$ \\
$\mathrm{C} 28-\mathrm{H} 28 A \cdots \mathrm{S} 4^{\text {viii }}$ & 0.99 & 3 & $3.759(5)$ & 135 \\
$\mathrm{C} 48-\mathrm{H} 48 \cdots \mathrm{O} 4^{\mathrm{iii}}$ & 0.95 & 2.43 & $3.361(5)$ & 165 \\
$\mathrm{C} 33-\mathrm{H} 33 \cdots \mathrm{S} 5^{\mathrm{iv}}$ & 0.95 & 2.82 & $3.446(5)$ & 124 \\
$\mathrm{C} 30-\mathrm{H} 30 A \cdots \mathrm{S} 1$ & 0.99 & 2.94 & $3.746(5)$ & 139 \\
$\mathrm{C} 18-\mathrm{H} 18 B \cdots \mathrm{S} 8^{\text {ix }}$ & 0.99 & 3.01 & $3.942(5)$ & 158 \\
$\mathrm{C} 44-\mathrm{H} 44 \cdots \mathrm{S} 1$ & 0.95 & 2.82 & $3.476(5)$ & 127 \\
$\mathrm{C} 29-\mathrm{H} 29 B \cdots \mathrm{S} 4^{\text {viii }}$ & 0.99 & 3 & $3.775(5)$ & 136 \\
$\mathrm{C} 38-\mathrm{H} 38 A \cdots \mathrm{S} 2$ & 0.99 & 2.99 & $3.891(5)$ & 151 \\
$\mathrm{C} 38-\mathrm{H} 38 B \cdots \mathrm{S} 3^{\mathrm{v}}$ & 0.99 & 2.99 & $3.877(5)$ & 149 \\
$\mathrm{C} 39-\mathrm{H} 39 B \cdots \mathrm{S} 8$ & 0.99 & 2.99 & $3.542(5)$ & 117 \\
$\mathrm{C} 31-\mathrm{H} 31 A \cdots \mathrm{S} 2^{\mathrm{x}}$ & 0.98 & 3 & $3.907(5)$ & 154 \\
$\mathrm{C} 52-\mathrm{H} 52 A \cdots \mathrm{S} 7$ & 0.99 & 2.97 & $3.788(5)$ & 140 \\
\hline
\end{tabular}

Symmetry codes: (i) $x-1, y+1, z$; (ii) $x+1, y-1, z$; (iii) $-x+1,-y+1,-z+2$; (iv) $-x,-y+2,-z+2$;

(v) $-x+1,-y+2,-z+1$; (vi) $x-1, y, z$; (vii) $-x+1,-y+2,-z+2$; (viii) $-x+2,-y+2,-z+1$;

(ix) $x, y-1, z ;(\mathrm{x})-x,-y+3,-z+1$. 
Table 4. Energy values for all species and HOMO-LUMO difference.

\begin{tabular}{|c|c|c|c|}
\hline Compound & $\begin{array}{c}\text { HOMO } \\
\text { (Hartrees) }\end{array}$ & $\begin{array}{c}\text { LUMO } \\
\text { (Hartrees) }\end{array}$ & Gap (eV) \\
\hline \multicolumn{4}{|c|}{ Cobalt complex } \\
(The energy value is followed by the type of orbital. In the case of full \\
optimization, the state is doubly for HOMO \\
or triply degenerate for LUMO) \\
\hline Co1(NCS) 4 \\
\hline Co2(NCS) 4 & $-0.01794(\beta)$ & $0.12975(\beta)$ & 4.02 \\
\hline Co(NCS)4 & $-0.01220(\beta)$ & $0.10401(\beta)$ & 3.16 \\
optimized & $-0.02368(\beta-2)$ & $0.12598(\beta-3)$ & 4.07 \\
\hline \multicolumn{3}{|c|}{ Organic ligand } \\
\hline Ligand 1 & -0.30710 & -0.17921 & 3.48 \\
\hline Ligand 2 & -0.32522 & -0.18053 & 3.93 \\
\hline Ligand 3 & -0.31491 & -0.17687 & 3.76 \\
\hline Ligand 4 & -0.31850 & -0.17213 & 3.97 \\
\hline optimized Ligand & -0.32276 & -0.17337 & 4.05 \\
\hline
\end{tabular}


Table 5. Mulliken charge distribution of all atoms in the anionic entities. The optimized complex having Td symmetry, only one value is given per atom type, the others being identical.

\begin{tabular}{|c|c|c|c|}
\hline Atom & Col & $\mathrm{Co} 2$ & $\begin{array}{c}\text { Full } \\
\text { optimization }\end{array}$ \\
\hline $\mathrm{Co}$ & 0.108987 & 0.129816 & 0.158761 \\
\hline $\mathrm{N}$ & $\begin{array}{l}-0.026222 \\
0.021113 \\
-0.036645 \\
-0.034596\end{array}$ & $\begin{array}{l}-0.026077 \\
0.014702 \\
-0.066309 \\
0.010496\end{array}$ & -0.004514 \\
\hline $\mathrm{C}$ & $\begin{array}{l}-0.122442 \\
-0.142222 \\
-0.096108 \\
-0.112098\end{array}$ & $\begin{array}{l}-0.113072 \\
-0.100890 \\
-0.132663 \\
-0.130392\end{array}$ & -0.144006 \\
\hline $\mathrm{S}$ & $\begin{array}{l}-0.394633 \\
-0.403412 \\
-0.383766 \\
-0.377956\end{array}$ & $\begin{array}{l}-0.400806 \\
-0.383882 \\
-0.400660 \\
-0.400263\end{array}$ & -0.391171 \\
\hline
\end{tabular}


Table 6. Mulliken charge distribution of all atoms in the organic entities and water molecule.

\begin{tabular}{|c|c|c|c|c|c|}
\hline Atom & Ligand 1 & Ligand 2 & Ligand 3 & Ligand 4 & $\begin{array}{c}\text { Full } \\
\text { optimisation }\end{array}$ \\
\hline N1 & -0.096733 & -0.152778 & -0.113903 & 0.047346 & 0.107427 \\
\hline N4 & -0.868458 & -0.870148 & -0.878678 & -0.910572 & -0.894452 \\
\hline \multirow[t]{2}{*}{$\mathrm{H}(\mathrm{N} 4)$} & 0.504667 & 0.507443 & 0.508902 & 0.507063 & 0.501141 \\
\hline & 0.506174 & 0.508293 & 0.501209 & 0.504538 & 0.503219 \\
\hline $\mathrm{C} 2$ & -0.368589 & -0.339598 & -0.364256 & -0.289409 & -0.046942 \\
\hline \multirow[t]{2}{*}{$\mathrm{H}(\mathrm{C} 2)$} & 0.247743 & 0.244152 & 0.258207 & 0.228132 & 0.263023 \\
\hline & 0.225496 & 0.232114 & 0.226771 & 0.247861 & 0.218494 \\
\hline C3 & -0.211380 & -0.233827 & -0.187176 & -0.186733 & -0.257906 \\
\hline \multirow[t]{2}{*}{$\mathrm{H}(\mathrm{C} 3)$} & 0.262028 & 0.261552 & 0.259699 & 0.257074 & 0.276803 \\
\hline & 0.275230 & 0.280408 & 0.277601 & 0.284430 & 0.256781 \\
\hline $\mathrm{C} 5$ & -0.266408 & -0.180090 & -0.383316 & -0.285046 & -0.252183 \\
\hline \multirow[t]{2}{*}{$\mathrm{H}(\mathrm{C} 5)$} & 0.278592 & 0.263049 & 0.258626 & 0.253489 & 0.256813 \\
\hline & 0.261911 & 0.279633 & 0.280345 & 0.319564 & 0.276744 \\
\hline C6 & -0.309067 & -0.362241 & -0.178547 & -0.233667 & -0.055007 \\
\hline \multirow[t]{2}{*}{ H(C6) } & 0.253214 & 0.235194 & 0.261251 & 0.260743 & 0.263087 \\
\hline & 0.223063 & 0.250334 & 0.218587 & 0.226632 & 0.218860 \\
\hline $\mathrm{C} 7$ & 0.055363 & 0.042041 & -0.065723 & -0.428181 & -1.536423 \\
\hline $\mathrm{C} 8$ & -0.053355 & 0.690209 & 0.605841 & 0.309632 & 0.106108 \\
\hline $\mathrm{H}(\mathrm{C} 8)$ & 0.169598 & 0.166082 & 0.175552 & 0.181797 & 0.194644 \\
\hline C9 & -0.622596 & -0.853254 & -0.605726 & -0.604308 & -0.098938 \\
\hline H(C9) & 0.210790 & 0.210308 & 0.211308 & 0.213780 & 0.211953 \\
\hline C10 & 0.087805 & -0.121534 & 0.034560 & 0.102400 & 0.047462 \\
\hline $\mathrm{C} 11$ & 0.035800 & -0.351001 & 0.466814 & -0.110553 & 0.518677 \\
\hline $\mathrm{H}(\mathrm{C} 11)$ & 0.194252 & 0.208859 & 0.197174 & 0.197152 & 0.194459 \\
\hline $\mathrm{C} 12$ & -0.087072 & 0.045674 & -1.088163 & -0.260463 & -0.403991 \\
\hline $\mathrm{H}(\mathrm{C} 12)$ & 0.169392 & 0.165180 & 0.182576 & 0.178707 & 0.176942 \\
\hline O13 & -0.378120 & -0.378819 & -0.373358 & -0.374132 & -0.371999 \\
\hline $\mathrm{C} 14$ & -0.337692 & -0.349981 & -0.325408 & -0.346148 & -0.325165 \\
\hline \multirow[t]{3}{*}{$\mathrm{H}(\mathrm{C} 14)$} & 0.207728 & 0.215748 & 0.224311 & 0.207287 & 0.211522 \\
\hline & 0.224095 & 0.191539 & 0.209032 & 0.204939 & 0.227356 \\
\hline & 0.206529 & 0.195457 & 0.205887 & 0.224221 & 0.21149 \\
\hline $\mathrm{O}\left(\mathrm{H}_{2} \mathrm{O}\right)$ & & & & -0.944665 & \\
\hline $\mathrm{H}\left(\mathrm{H}_{2} \mathrm{O}\right)$ & & & & $\begin{array}{l}0.510343 \\
0.506745\end{array}$ & \\
\hline
\end{tabular}


Table 7. Chemical proportions on the Hirshfeld surface, $\%$ contact types and their enrichment ratios. The major interaction types and the most enriched are in bold. The hydrogen atoms ( $\mathrm{Ho} / \mathrm{n}$ and, $\mathrm{Hc}$ ) bound to $\mathrm{O} / \mathrm{N}$ and $\mathrm{C}$ are distinguished, as their chemical properties are different.

\begin{tabular}{|c|ccccccc|}
\hline Atom & $\mathrm{Ho} / \mathrm{n}$ & $\mathrm{C}$ & $\mathrm{N}$ & $\mathrm{O}$ & $\mathrm{S}$ & $\mathrm{Co}$ & $\mathrm{Hc}$ \\
surface $\%$ & 6.5 & 21.0 & 3.9 & 3.1 & 21.8 & 3.7 & 40.0 \\
\hline $\mathrm{Ho} / \mathrm{n}$ & 0.0 & & & & & & \\
$\mathrm{C}$ & 2.3 & 4.1 & & actual & contacts & Cxy & \\
$\mathrm{N}$ & 2.6 & 0.4 & 0.2 & & & & \\
$\mathrm{O}$ & 2.0 & 0.3 & 0.0 & 0.0 & & & \\
$\mathrm{~S}$ & 3.9 & $\mathbf{6 . 3}$ & 1.9 & 0.1 & 1.3 & & \\
$\mathrm{Co}$ & 1.0 & 0.1 & 0.0 & 0.3 & 3.6 & 0.0 & \\
$\mathrm{Hc}$ & 1.1 & $\mathbf{2 4 . 2}$ & 2.4 & 3.5 & $\mathbf{2 5 . 2}$ & 2.4 & $\mathbf{1 0 . 6}$ \\
\hline $\mathrm{Ho} / \mathrm{n}$ & 0.01 & & & & & & \\
$\mathrm{C}$ & 0.86 & 0.94 & & & enrichment & Exy & \\
$\mathrm{N}$ & $\mathbf{5 . 2 3}$ & 0.27 & 1.23 & & & & \\
$\mathrm{O}$ & $\mathbf{4 . 9 7}$ & 0.24 & 0.09 & 0.00 & & & \\
$\mathrm{~S}$ & $\mathbf{1 . 3 6}$ & 0.68 & 1.09 & 0.08 & 0.28 & & \\
$\mathrm{Co}$ & 2.08 & 0.08 & 0.02 & 1.32 & 2.23 & 0.00 & \\
$\mathrm{Hc}$ & 0.22 & $\mathbf{1 . 4 4}$ & 0.78 & $\mathbf{1 . 3 9}$ & $\mathbf{1 . 4 4}$ & 0.80 & 0.66 \\
\hline
\end{tabular}

Table 8. Analysis of contacts types and their enrichment between the layer of Co(NCS $)_{4}$ anions and the layer of organic cation + water. In the first two lines, the chemical description of the Hirshfeld surface on anion side is given. In the first two columns the surface content on the cation+water side is given. The major and enriched contact types are in bold. Enrichment ratios of $\mathrm{N}$ and $\mathrm{O}$ atoms on the cation side are omitted as their proportion is very small on the interface.

\begin{tabular}{|c|c|c|c|c|c|c|}
\hline $\begin{array}{l}\text { atom } \\
\text { type }\end{array}$ & $\begin{array}{l}\text { surface } \\
(\%)\end{array}$ & $\begin{array}{c}\text { C } \\
19.3\end{array}$ & $\begin{array}{c}\mathbf{N} \\
8.2\end{array}$ & $\begin{array}{c}\mathbf{S} \\
65.5\end{array}$ & $\begin{array}{c}\text { Co } \\
7.0\end{array}$ & $\mathrm{Co}(\mathrm{NCS})_{4}$ \\
\hline Ho/n & 17.4 & 3.0 & 4.6 & 7.7 & 2.0 & $C_{\mathrm{xy}}$ \\
\hline C & 8.9 & 1.7 & 0.3 & 7.1 & 0.0 & actual \\
\hline $\mathbf{N}$ & 1.3 & 0.0 & 0.3 & 1.1 & 0.0 & contacts \\
\hline O & 1.0 & 0.2 & 0.1 & 0.1 & 0.5 & $(\%)$ \\
\hline Hc & 71.3 & 14.5 & 3.1 & 49.4 & 4.3 & \\
\hline Ho/n & organic & 1.15 & 4.14 & 0.87 & 2.15 & $E_{\mathrm{xy}}$ \\
\hline $\mathbf{C}$ & cation & 1.24 & 0.48 & 1.57 & 0.07 & enrich- \\
\hline Hc & $+\mathrm{HOH}$ & 1.37 & 0.68 & 1.37 & 1.11 & ment \\
\hline
\end{tabular}

